\title{
Anisometric Brain Dimorphism Revisited: Implementation of a Volumetric 3D Standard Brain in Manduca sexta
}

\author{
BASIL EL JUNDI, WOLF HUETTEROTH, ANGELA E. KURYLAS, AND JOACHIM SCHACHTNER* \\ Department of Biology, Animal Physiology, Philipps-University, Marburg, Germany
}

\begin{abstract}
Lepidopterans like the giant sphinx moth Manduca sexta are known for their conspicuous sexual dimorphism in the olfactory system, which is especially pronounced in the antennae and in the antennal lobe, the primary integration center of odor information. Even minute scents of female pheromone are detected by male moths, facilitated by a huge array of pheromone receptors on their antennae. The associated neuropilar areas in the antennal lobe, the glomeruli, are enlarged in males and organized in the form of the so-called macroglomerular complex (MGC). In this study we searched for anatomical sexual dimorphism more downstream in the olfactory pathway and in other neuropil areas in the central brain. Based on freshly eclosed animals, we created a volumetric female and male standard brain and compared 30 separate neuropilar regions. Additionally, we
\end{abstract}

labeled 10 female glomeruli that were homologous to previously quantitatively described male glomeruli including the MGC. In summary, the neuropil volumes reveal an isometric sexual dimorphism in $M$. sexta brains. This proportional size difference between male and female brain neuropils masks an anisometric or disproportional dimorphism, which is restricted to the sex-related glomeruli of the antennal lobes and neither mirrored in other normal glomeruli nor in higher brain centers like the calyces of the mushroom bodies. Both the female and male 3D standard brain are also used for interspecies comparisons, and may serve as future volumetric reference in pharmacological and behavioral experiments especially regarding development and adult plasticity. J. Comp. Neurol. 517:210-225, 2009.

๑) 2009 Wiley-Liss, Inc.

Indexing terms: brain; olfactory system; antennal lobe; insect; neuropil; digital neuroanatomy

Brains are typically organized in defined substructures or modules, which can usually be characterized by their spatial location, gross anatomy, and often by a certain function. For example, in vertebrates the olfactory bulbs and in insects the antennal lobes have been attributed to be the first processing centers for olfactory information (for a review, see Hildebrand and Shepherd, 1997). Olfactory bulbs and antennal lobes (ALs) can be found at the entrance of the olfactory nerve or the antennal nerve in the brain. They are typically comprised of olfactory glomeruli which represent functional units for odor processing containing thousands of synapses between olfactory sensory neurons (OSNs) from the olfactory epithelium/ antenna and neurons of the olfactory bulbs/ALs. Each glomerulus receives input from OSNs expressing particular odorant receptors (Vosshall, 2000; Korsching, 2002; Jefferis and Hummel, 2006; Mombaerts, 2006) and odors are finally encoded by activation patterns of defined sets of glomeruli, resulting in a spatial odor map and a chemotopic representation of odor information in the brain (Galizia et al., 1999; Leon and Johnson, 2003; Wang et al., 2003; Vosshall and Stocker, 2007; Namiki and Kanzaki, 2008; Staudacher et al., 2009). Depending on the species, the complexity of the brain, which is expressed by the number and the complexity of brain modules, is extremely variable.
Compared to most vertebrate brains, insect brains are miniature versions typically comprised of a lower number of neurons and modules. Owing to the lower complexity and certain technical advantages, insects have been widely used as models to study principal mechanisms of information processing and integration, in the context of defined sensory inputs but also complex behaviors including learning (e.g., Menzel, 2001; Heisenberg, 2003).

Brains of animals of the same or of evolutionary related species typically share the same principal organization. For example, in neopteran insects the central olfactory pathway

Additional Supporting Information may be found in the online version of this article.

Grant sponsor: Deutsche Forschungsgemeinschaft; Grant number: Scha 678/3-3 (to J.S.)

The first two authors contributed equally to this work.

*Correspondence to: J. Schachtner, Department of Biology, Animal Physiology, Philipps-University, Karl-von-Frisch-Strasse 8, D-35032 Marburg, Germany. E-mail: schachtj@staff.uni-marburg.de

Received 27 June 2008; Revised 5 December 2008; Accepted 1 July 2009 DOI 10.1002/cne.22150

Published online July 17, 2009 in Wiley InterScience (www.interscience.wiley. com). 
seems to be well conserved (Strausfeld et al., 1998; Schachtner et al., 2005). However, even within the same species, no brain is identical with the next, differing in size and shape of certain brain modules. These individual differences can result from a variety of parameters that influence brain organization during development but also during adulthood. In insects, such factors include brood temperature, sex, age, and experience (Groh et al., 2004; Technau, 2007; Molina and O'Donnell, 2008).

To study sexual brain dimorphism or the influence of defined parameters - ranging from single molecules to social experience- on brain development or adult plasticity, average or standardized brains or brain areas are needed to overcome the problem of individual variations. Advances in imaging techniques, 3D reconstruction software, and computer power led so far to $3 \mathrm{D}$ reconstructions and subsequent standardization of brain areas of three insect species, including Drosophila (Rein et al., 2002; Jenett et al., 2006), the honeybee (Brandt et al., 2005), and the desert locust (Kurylas et al., 2008). To obtain such a standard insect brain, two methods have so far been established: the virtual insect brain (VIB) protocol and the iterative shape averaging (ISA) method. The main rationale for the development of the VIB protocol was to compare brain areas between wildtype and genetically manipulated Drosophila (Rein et al., 2002; Jenett et al., 2006). The ISA method, first used for the honeybee, was primarily aimed to register single reconstructed neurons from various individuals into one standard brain (Rohlfing et al., 2004; Brandt et al., 2005). According to Kurylas et al. (2008), who compared both protocols for the standardization of the brain of the desert locust, each protocol has its advantages. The VIB script, which preserves volumetric consistency in the process of standardization, is ideally suited for inter- and intraspecific comparisons of neuropils, including sex-specific differences (Kurylas et al., 2008). The ISA method, on the other hand, which provides a better representation of relative locations of brain areas, is the choice to produce a brain atlas, which can be used as a framework to register neurons or neuron populations from different individuals (Ku $\boldsymbol{\beta}$ et al., 2007; Kurylas et al., 2008).

In the current study, we reconstructed in three dimensions and subsequently standardized brain areas of both sexes of the sphinx moth Manduca sexta using the VIB protocol. $M$. sexta has served for decades as a model to study development, information processing, and plasticity, especially of the olfactory system (for review, see, e.g., Tolbert et al., 2004). The goals of our study were to 1) compare adult brain neuropil volumes regarding sexual dimorphism; 2) provide an adult female and male standard brain as volume references for future pharmacological and behavioral studies; 3) look for allometric relations of neuropils in a lepidopteran species; 4) compare in detail selected ordinary olfactory glomeruli in female and male antennal lobes regarding further sex-specific dimorphism apart from the described three sex-dimorphic glomeruli (Rospars and Hildebrand, 2000; Huetteroth and Schachtner, 2005); and 5) compare the standard volumes of brain areas with previously published standard volumes of homologous brain areas of other neopteran insects.

\section{MATERIALS AND METHODS Animals}

Moths (M. sexta; Lepidoptera: Sphingidae) were kept in walk-in environmental chambers at $26^{\circ} \mathrm{C}$ under a long-day photoperiod (L:D = 17:7) and were fed an artificial diet (Bell and Joachim, 1978). Under these conditions only freshly eclosed adults were weighed and prepared for reconstruction. For generation of a female and a male standard brain we used 12 female brains and 12 male brains. For the glomerulus volumes of the female antennal lobe we reconstructed 11 antennal lobes of brains, which were in part also used for the female standard brain. Volume values of 16 male antennal lobes were taken from Huetteroth and Schachtner (2005).

\section{Immunohistochemistry}

For wholemount staining we adapted and refined the staining protocols described by Huetteroth and Schachtner (2005) and Kurylas et al. (2008). The whole brains were dissected under cold saline (Weevers, 1966) and fixed subsequently at $4^{\circ} \mathrm{C}$ overnight in a solution composed of one part formaldehyde ( $37 \%$, Roth, Karlsruhe, Germany), one part methanol, and eight parts phosphate-buffered saline (PBS $0.01 \mathrm{M}, \mathrm{pH}$ 7.4). These brains were then rinsed in $0.01 \mathrm{M}$ PBS for 1 hour at room temperature followed by preincubation overnight at $4^{\circ} \mathrm{C}$ in 5\% normal goat serum (NGS; Jackson ImmunoResearch, Westgrove, PA) in $0.01 \mathrm{M}$ PBS containing $0.3 \%$ Triton X-100 (PBST) and $0.02 \%$ sodium azide. The monoclonal primary antibody from mouse against a fusion protein consisting of a glutathione-S-transferase and the first amino acids of the presynaptic vesicle protein synapsin I coded by its $5^{\prime}$-end (SYNORF1, Klagges et al., 1996) was used to selectively label neuropilar areas in the brain (3C11, \#151101 (13.12.06), kindly provided by Dr. E. Buchner, Würzburg). Its specificity in $M$. sexta was shown in Western blots by Utz et al. (2008). It was diluted 1:100 in PBST containing 1\% NGS: in this solution the brains were incubated for $5-6$ days at $4^{\circ} \mathrm{C}$.

Subsequently the brains were rinsed six times in 2 hours with PBST before they were incubated with the secondary goat antimouse antibody conjugated to Cy5 (1:300, catalog code 115-175-146, lot 71608, Jackson ImmunoResearch) in PBST and $1 \%$ NGS for 4 days at $4^{\circ} \mathrm{C}$. After this time the brains were rinsed again with PBST six times in 2 hours. Thereafter the brains were dehydrated in an ascending alcohol series (50\%-100\%, 15 minutes each) and then cleared in methyl salicylate (Merck, Gernsheim, Germany) for about 40 minutes. Finally, the brains were mounted in Permount (Fisher Scientific, Pittsburgh, PA) between two coverslips using 10 spacers (Zweckform, Oberlaindern, Germany) to prevent compression of brains.

\section{CLSM image acquisition and processing}

The wholemount preparations were scanned at $512 \times 512$ pixel resolution by using a $10 \times$ oil immersion objective (HC PL APO 10x / NA: $0.40 \mathrm{Imm}$ [working distance: $0.36 \mathrm{~mm}$; Leica, Bensheim, Germany) with a confocal laser scanning microscope (Leica TCS SP2). All brains were scanned with a voxel size of $2.9 \times 2.9 \times 2 \mu \mathrm{m}$. The thickness of the brain $(\approx 700 \mu \mathrm{m})$ and the limited working distance of the objective $(\approx 450 \mu \mathrm{m})$ made it necessary to scan the brain from both sides (anterior and posterior) to eventually acquire images of the whole brain. As a result of the brain width $(\approx 4-5 \mathrm{~mm})$ it was necessary to 
scan up to four batches of data from anterior and posterior. Thus, we obtained a total of six to eight image stacks (three to four from anterior and the same from posterior) which together represented the complete brain.

Antennal lobes were scanned at $512 \times 512$ pixel resolution using the $10 \times$ oil immersion objective in one image stack. The antennal lobes were scanned with a voxel size of $1.46 \times$ $1.46 \times 1.5 \mu \mathrm{m}$ and with a zoom factor of 2 .

Processing of scanned stacks for reconstruction was performed basically as described by Kurylas et al. (2008): For the whole brains we found in the $z$ direction corresponding optical slices in the overlapping part of both image stacks with the module "AlignSlices" in the program AMIRA 4.1 (Visage Imaging, Fürth, Germany). Redundant slices of the stacks were abolished and corresponding batches of data were merged with the module "AlignSlices." Thereby four batches of data were obtained. Before we merged these image stacks in $x y$ direction, computation limits made it necessary to downsample the voxel size. With the module "Resample" we achieved image stacks with a voxel size of $6 \times 6 \times 6 \mu \mathrm{m}$, which allowed for merging the batch of data in $x y$ direction. Again, we used the module "AlignSlices" for finding the corresponding optical slice and with the module "Merge" the four batches of data were merged into one batch of data that contained the whole brain.

\section{Image segmentation, reconstruction, standardization, and visualization}

The selected neuropils and individual olfactory glomeruli were labeled with the segmentation editor in AMIRA on a PC running Windows XP Pro (Intel Core2 6600, 2 GB RAM, ATI Radeon X1800). For segmentation and reconstruction details we principally refer to Kurylas et al. (2008). In short, semiautomatically created voxel-based label fields of 14 paired and 3 unpaired neuropilar structures in 12 female and 12 male $M$. sexta brains provided the underlying matrix of all computation processes performed (i.e., polygonal surface models, morphometric analysis, shape averaging). Brain outlines were reconstructed separately and serve as orientation guidance only. The color codes for neuropilar areas and antennal lobe glomeruli are consistent with previous works (Brandt et al., 2005; Huetteroth and Schachtner, 2005; Kurylas et al., 2008). The AMIRA label field file used for color coding of the various selected neuropils can be downloaded online (Suppl. 1).

The VIB protocol for registration and standardization was described in detail by Jenett et al. (2006) and is accessible at http://www.neurofly.de. All functions of the VIB protocol have been implemented in the AMIRA graphical environment (Jenett et al., 2006). The application of the VIB protocol requires a template brain that defines the position of individual neuropils in the visualized standard brain (Jenett et al., 2006). To overcome a subjective bias for the selection of the template brain, we calculated the relative position of all reconstructed neuropils of each analyzed brain and choose as a template the brain with the lowest variance of the brain areas to the relative mean distance of all labeled neuropils (see Results). It is important to note that the choice of the template brain has no effect on the resulting standard volumes (Kurylas et al., 2008). For creation of standard brain neuropil labels, we chose an overlap threshold of $50 \%$ for large neuropils, and $30 \%$ for small neuropils.
Additional analysis of these data was achieved using Excel XP and SPSS 11.5 (SPSS, Chicago, IL) for Windows. The synapsin-immunoreactivity (syn-ir) in Figures 1 and 7 was autocontrasted in the OrthoSlice module of AMIRA, and transparent colored labels were added using Adobe Photoshop 8 (Adobe Systems, San Jose, CA). For 3D visualization, respective label surfaces were exported from AMIRA and visualized with CINEMA 4D (v. 10.1; MAXON Computer, Friedrichsdorf, Germany). Pictures edited in Photoshop (Figs. 1, 7) and snapshots from CINEMA 4D were compiled with Corel Draw 12 (Corel, Ottawa, ON, Canada) without any further modification on brightness or contrast.

\section{RESULTS \\ Reconstructed neuropils}

Of all major areas of the lepidopteran brain we reconstructed those which we were able to unambiguously delimit in all three dimensions (14 paired and 2 unpaired neuropils). In the optic lobe, our $M$. sexta female and male standard brains are the first to include the lamina (La) (Fig. 1A,A'). Median to the lamina lies the medulla (Me) and posteromedian to this neuropil we reconstructed the lobula plate (LoP), a neuropil exclusively found in Ephemeroptera, Trichoptera, Coleoptera, Diptera, and Lepidoptera (Strausfeld, 2005). For the reconstruction we subdivided the lobula into two discernible subunits, the outer (Loo) and the inner lobula (Loi) (Fig. $\left.1 \mathrm{~B}, \mathrm{~B}^{\prime}, \mathrm{C}, \mathrm{C}^{\prime}\right)$; anterior of the lobula we labeled the accessory medulla (aMe).

In the central brain we divided the mushroom bodies into two neuropils, the pedunculus $(\mathrm{Pe})$, which contained all lobes, and the calyx (Ca) (Fig. 1D,D') according to an earlier insect brain standard (Kurylas et al., 2008). Although visible, we refrained from including subunits as described for the moth Spodoptera littoralis (Sjöholm et al., 2005) or Bombyx mori (Fukushima and Kanzaki, 2009); the resulting complexity of the pedunculi would have greatly interfered with standardization procedures, and would have also interfered with interspecies comparison. Nevertheless, all four lobes of the pedunculus, the $\alpha-, \beta-, \gamma-$, and Y-lobe (Pearson, 1971), are discernible

Figure 1.

Confocal images of an individual $M$. sexta brain stained with $\alpha$-synapsin antibody. This brain was used as a template for the VIB protocol. A-D: Confocal slices through the brain. A'-D': All manually labeled neuropil areas as reconstructed in AMIRA. E,E': Dorsal views. $A, A^{\prime}$ : Axial slice through the $M$. sexta brain at the level of the antennal lobes $(\mathrm{AL})$ and the accessory medullae $(\mathrm{aMe})$ at $\approx 150 \mu \mathrm{m}$ depth. The lamina (La) and medulla (Me) span over all slices. B,B': Axial slice at the level of the lobes of the mushroom bodies $(\mathrm{Pe})$ and the three subunits of the anterior optic tubercle (upper, lower and nodular unit; uAOTu, IAOTu, nAOTu) at $\approx 300 \mu \mathrm{m}$ depth. Additionally, outer (Loo) and inner lobula (Loi) appear. C,C': Image of the brain at the level of the central body subunits (upper and lower unit; CBU and CBL) and the paired noduli (No) at $\approx 400 \mu \mathrm{m}$ depth. Note the horizontally oriented pedunculi and continuing optic neuropils. D,D': At the posterior end of the brain at a depth of $\approx 600 \mu \mathrm{m}$ the pedunculi of the mushroom bodies merge into the calyces (Ca). E,E': Horizontal slice through the brain at the level of the upper unit of the central body (CBU) at $\approx 400$ $\mu \mathrm{m}$ depth. Note the lobula plate (LoP) and the protocerebral bridge (PB) at their posterior position in the brain. The color code of the neuropilar areas is consistent with Brandt et al. (2005) and Kurylas et al. (2008). Scale bar $=500 \mu \mathrm{m}$. 


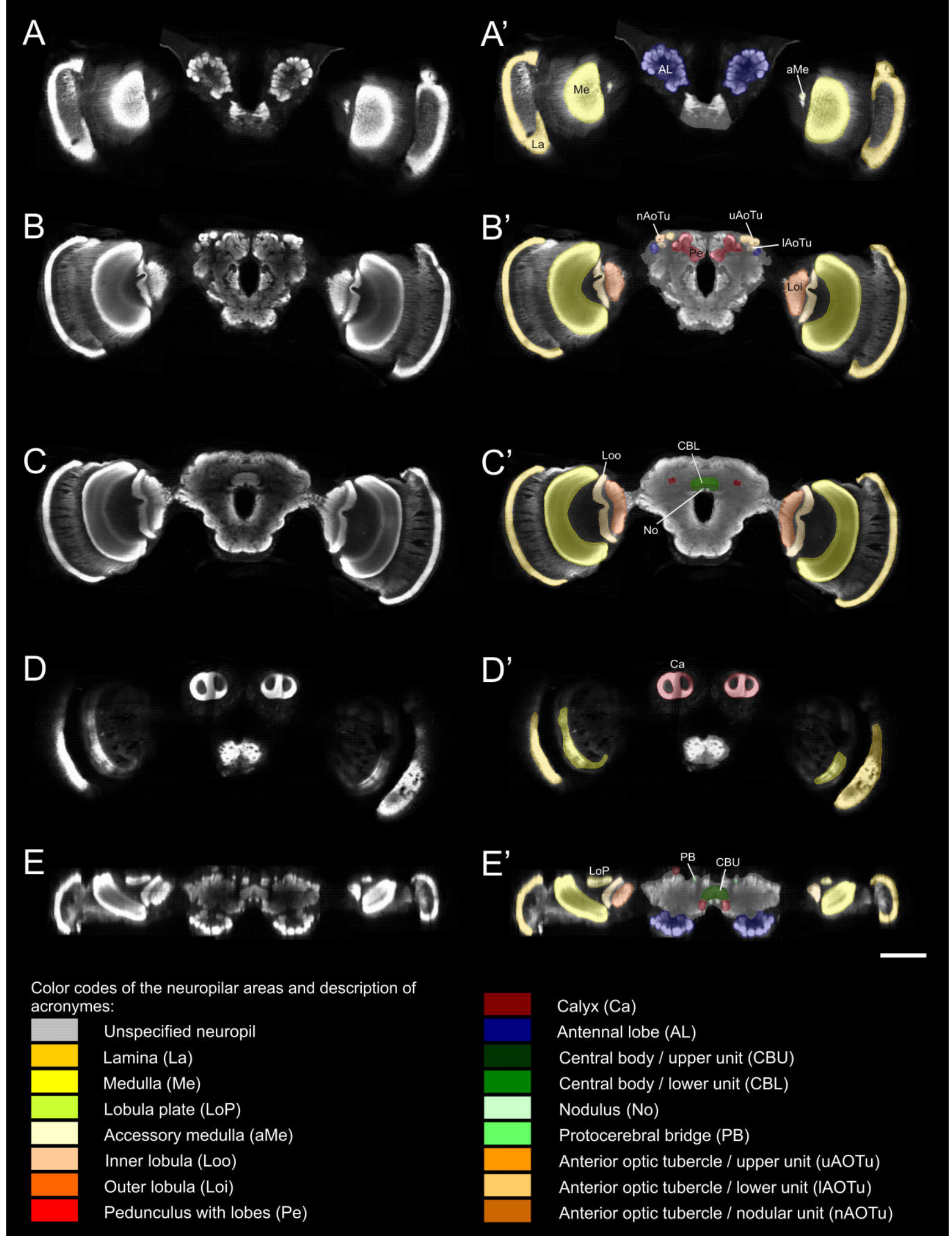




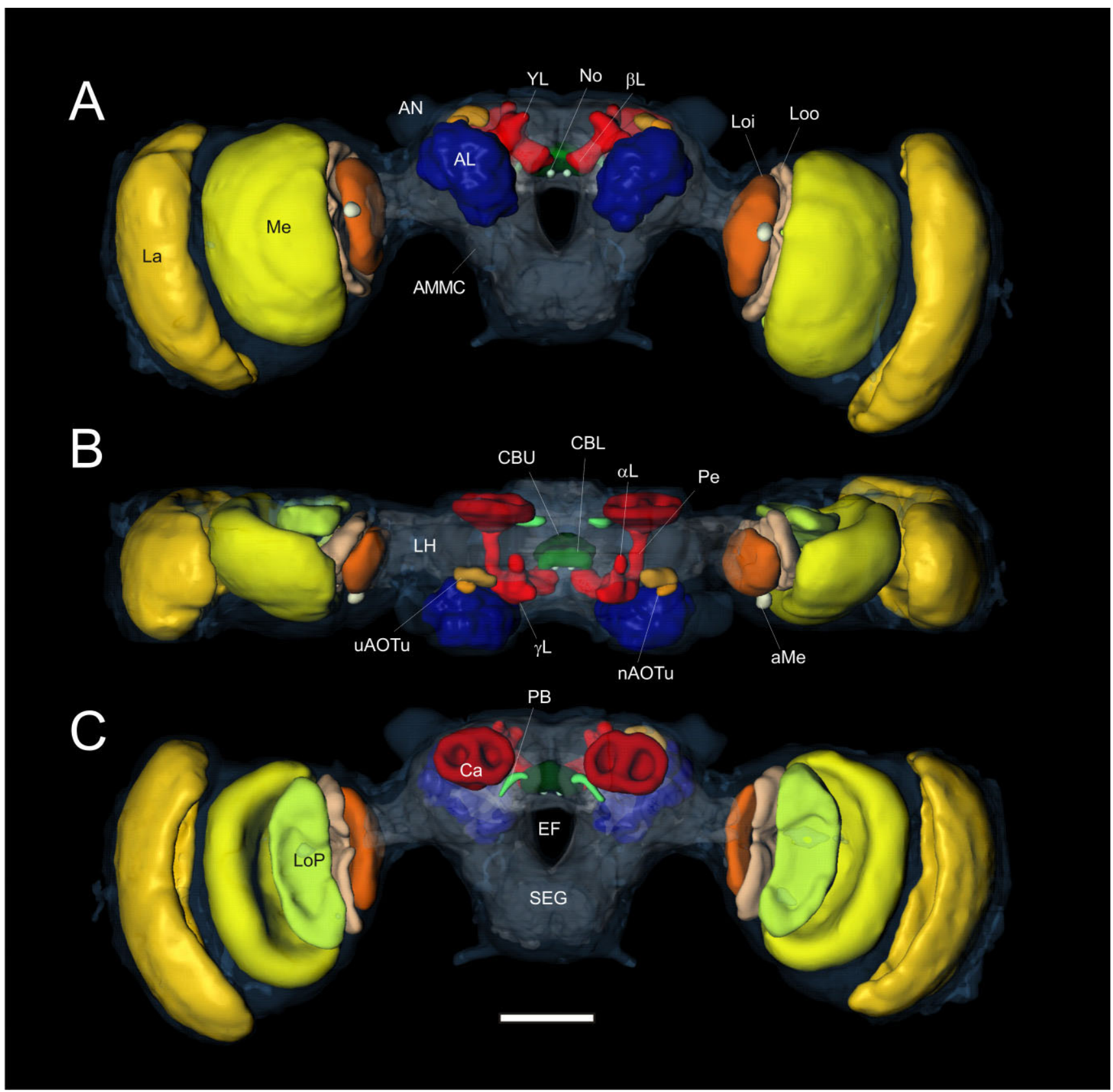

Figure 2.

The 3D female template brain of $M$. sexta in anterior (A), dorsal (B), and posterior view (C). The different lobes of the mushroom bodies $(\boldsymbol{\alpha}$-, $\beta$-, $\gamma-$, and Y-lobes) are merged with the pedunculus neuropil, but can be discerned as distinct protrusions (see Results). The lower unit of the anterior optic tubercle (IAOTu) is superposed by other neuropils and not visible here. In $M$. sexta, the subesophageal ganglion (SEG) is fused with the brain, thus forming the esophageal foramen (EF). See Figure 1 for color code and abbreviations. Scale bar $=500 \mu \mathrm{m}$.

protrusions in our reconstruction (Fig. 2). Between the mushroom bodies lies the central complex, which comprises the protocerebral bridge (PB), the upper and lower unit of the central body (CBU, CBL), and a small paired neuropil ventrally attached to the central body, the noduli (No) (Fig. 1C,C',E,E'). Synapsin-immunoreactivity (syn-ir) failed to label the connecting middle part of the two PB parts, which consists of tracts only. We restricted the label for the PB to these two halves, because all labels here and in other insect standard brains are based on syn-ir exclusively. The anteriormost labeled neuropils were the deutocerebral antennal lobes (AL), posterior to them in the protocerebrum we discerned three subunits of the anterior optic tubercle (AOTu), an upper (UAOTu), lower (IAOTu), and nodular unit (nAOTu).

All neuropilar areas that could not be associated with any of the neuropils mentioned above or could not be separated 


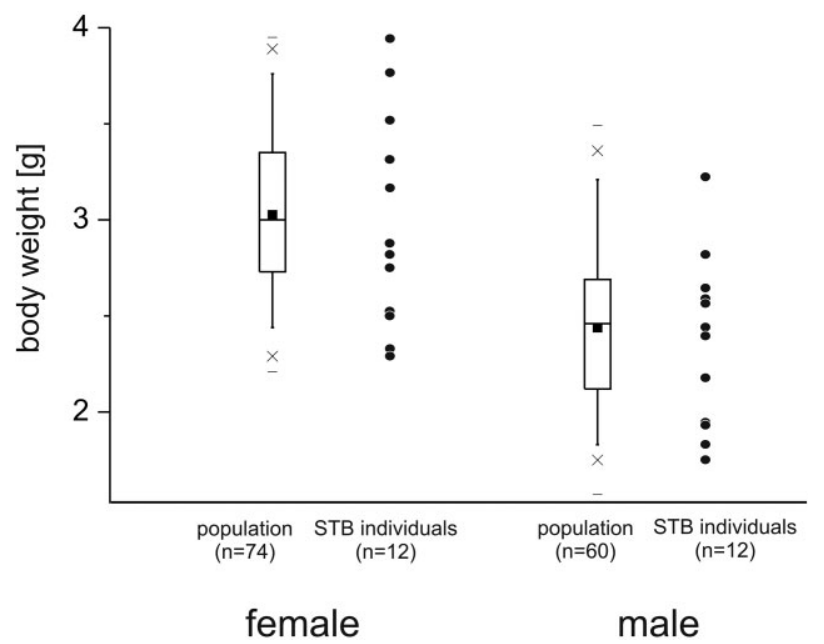

Figure 3.

Comparison of mean body weights of females $(n=74)$ and males $(n=$ 60 ) on their first day after adult eclosion. Black squares = mean weight; black horizontal lines = median; boxes = interquartile range; whiskers $=5$ th and 95th percentile, respectively; gray crosses $=1 \mathrm{st}$ and 99th percentile, respectively; gray horizontal lines = maximal and minimal individual weights. Aside are individual weights of 12 females and 12 males (black dots) which were used for standard brain (STB) reconstruction.

clearly were assigned to "unspecified neuropil." Notably, this material contains the antennal mechanosensory and motor center, the lateral accessory lobe, the superior, inferior, and lateral protocerebrum with the lateral horn, the subesophageal ganglion neuropil, and the tritocerebrum.

Representative outlines of all labels of these selected neuropils are shown in frontal and horizontal slices (Fig. 1), an animation of all orthogonal sections of this brain can be found in the supplementary material (Suppl. 2). Additionally, all reconstructed neuropils are displayed three-dimensionally to provide a 3D visualization of the whole brain (Fig. 2).

\section{Standard brains}

To apply the VIB protocol on the 3D brain reconstructions, one brain reconstruction had to be chosen as positional reference (Jenett et al., 2006). To reduce a subjective bias in the selection of this reference or template brain, we selected the template brain by calculating the distances of the centers of each of the reconstructed neuropils to the center of the respective brains. As template brain we selected for each sex the brain with the minimal total difference to the mean distance (Suppl. 3). The template brain used for generating the female standard brain is shown in Figures 1 and 2.

For the female and the male standard brain we reconstructed selected neuropils of 12 individual female and 12 individual male brains of $M$. sexta. To reduce bias between different individuals and to exclude adult-specific neuronal plasticity effects only freshly eclosed adults were used. The average weight of the 12 female animals used was $2.99 \mathrm{~g} \pm$ $0.56 \mathrm{~g}$ and lies within the mean weight of $3.03 \pm 0.41 \mathrm{~g}$ (Fig. 3; $n=74$ ). The average weight of the 12 male animals was $2.35 \mathrm{~g}$ $\pm 0.44 \mathrm{~g}$ and is also within $95 \%$ of a population of 60 male animals (Fig. 3).
With the VIB protocol we generated 3D standard atlases of both sexes consisting of 30 neuropils (14 paired and 2 unpaired neuropils), including both hemispheres of the brain. To visualize the "unspecified neuropil" in the female and male standard brain, we reconstructed the "unspecified neuropil" based on the standardized average gray images obtained by the VIB protocol (Fig. 4A'-C'). The neuropil surface models of the standard brain are shown in Figure $4 A-C$ from anterior, dorsal, and posterior. The displayed outline of the brain (Fig. $4 \mathrm{~A}-\mathrm{C}$, transparent) is not standardized and used for orientation and approximate proportion reasons only. Volume rendering of all 12 label images after non-rigid registration reveal the high quality of registration; only minor deviations in the laminae are visible (Fig. 4D,E). An animated view of the standard brain can be seen in the online supplement (Suppl. 4).

The VIB protocol also generates the standard volumes for each of the reconstructed brain areas of the 12 female and 12 male brains, respectively. Table 1 gives mean volumes, standard deviation, and standard error of absolute and relative volumes of all 30 areas plus the "unspecified neuropil." Volumes of corresponding neuropils in each hemisphere exhibited no significant difference in either $\operatorname{sex}(P>0.19$, two-tailed $t$-test).

\section{Brain size and body weight}

In some insects, body weight was shown to correlate with brain size (Mares et al., 2005). In our study we encountered notable differences in body weight (Fig. 3). Since the animals chosen for brain reconstruction span almost the whole weight range of adult $M$. sexta, it was straightforward to calculate neuropil size / body weight correlations. Although our heaviest female and male animals showed almost twice the weight than the smallest animals, we did not find significant allometric correlation between body weight and any neuropil volume in freshly eclosed animals (Fig. 5; Suppl. 5). The only exception was the female pedunculi, which exhibited a positive correlation $(P<0.05$; Fig. 5D).

\section{Comparison of the female and male brains}

We created the female and the male standard brain based on 12 freshly eclosed individuals of each sex, to allow for sex-specific comparison of brain neuropils (Fig. 6, Suppl. 6). In our Manduca colony the average weight of the males $(2.44 \pm$ $0.44 \mathrm{~g} ; n=60$ ) differed significantly from the female average weight of $3.03 \pm 0.41 \mathrm{~g}(n=74 ; P<0.05$, two-tailed $t$-test, Fig. $3)$. Accordingly, the volumes of selected neuropils of the male brain are smaller compared to the female brain. Congruent with allometric findings in ant brains (Wehner et al., 2007), we compared the standard volumes of the female neuropils with corresponding standard volumes of the male brains to study whether neuropils are significantly different (Fig. 6). Almost all neuropils of the female brain are larger than their male counterparts (Fig. 6A,B). Two neuropils, the accessory medulla (aMe) and the antennal lobe ( $\mathrm{AL}$ ), showed no significant volume differences between female and male brains. After normalizing neuropilar volumes to overall neuropil volume, no significant differences in neuropil volumes between sexes were left except for the aMe $(P<0.05)$ and the $\mathrm{AL}(P<0.001)$ (Fig. 6C,D).

In summary, with those two exceptions, we found an isometric sexual dimorphism for all standardized neuropil vol- 

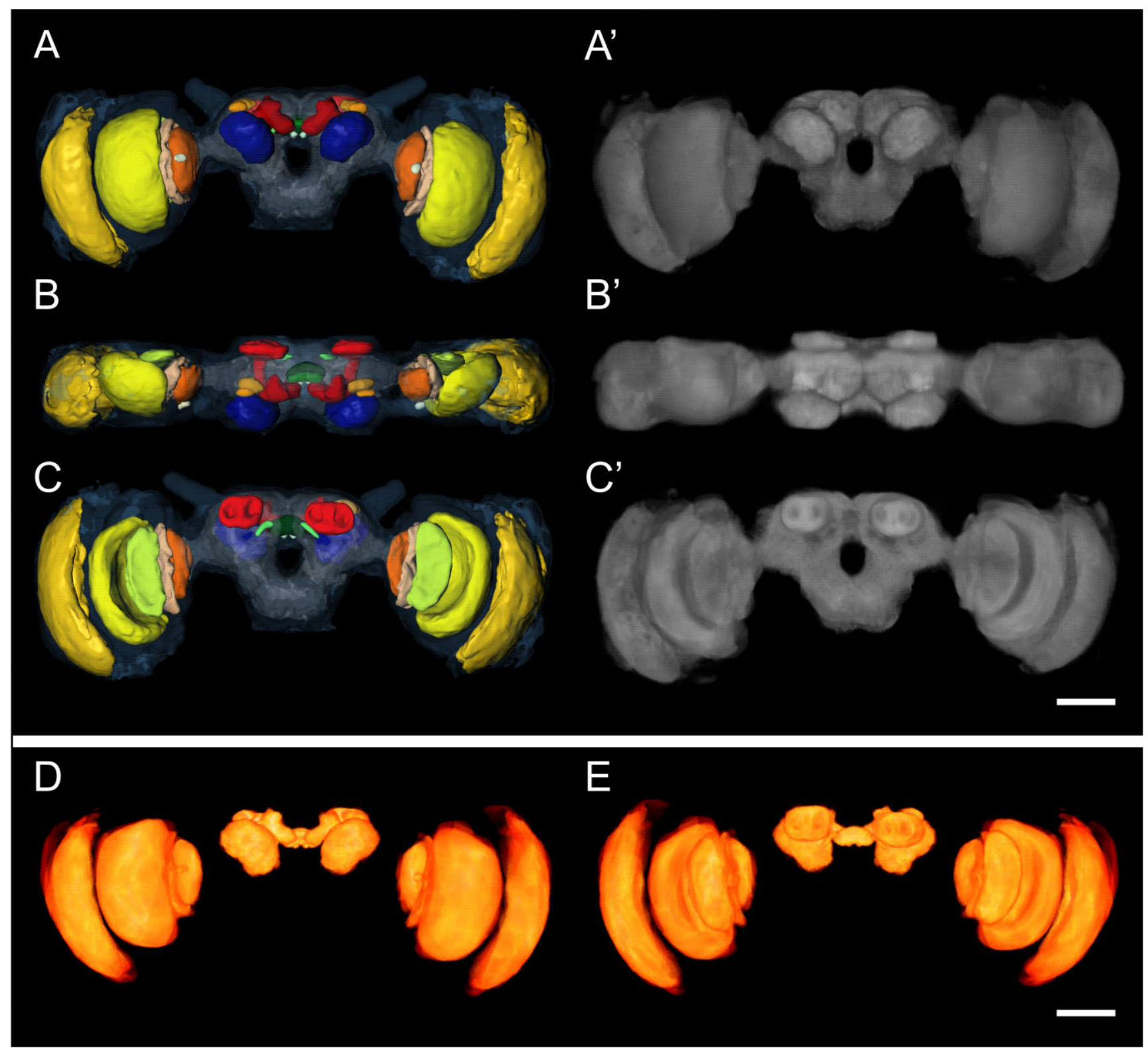

Figure 4.

The 3D female standard brain of M. sexta $(n=12)$, calculated using the VIB protocol (see Materials and Methods). A-C: Surface reconstructions of all 30 averaged labels in anterior (A), dorsal (B), and posterior view (C). The transparent blue neurilemma surface is not standardized and displayed for orientation only; the label of the unspecified neuropil (gray label) is based on the average image data. A'-C': 3D visualization of the corresponding average intensity map by direct volume rendering ( $A^{\prime}$ : anterior; C' dorsal; D': posterior). The color code refers to Figure 1. Even smaller neuropils retained their typical shape (e.g., protocerebral bridge, noduli) and give an optic measure of little brain variability as well as labeling quality. D,E: Direct volume rendered view of the resulting average label images from anterior (D) and posterior (E), exhibiting only minor deviations in the laminae. Scale bars $=500 \mu \mathrm{m}$.

umes, with the male volumes being 0.76 the size of the female counterparts on average.

\section{Male-female antennal lobe and glomerulus comparison}

Since the antennal lobe (AL) remained as the only highly significant anisometric sex-dimorphic neuropil in the brain of $M$. sexta, we focused on this region in more detail and labeled the volumes of 10 established glomeruli in 11 female ALs (Fig.
7A'). These glomeruli included three well-described sexspecific glomeruli, the lateral (ILFG) and the medial large female glomerulus (mLFG) as well as the small female glomerulus (SFG) (Fig. 7C,C'), which are homologous to the malespecific glomeruli cumulus, toroid, and horseshoe or toroid 2 (Rospars and Hildebrand, 2000). Additionally, we labeled seven easily identifiable glomeruli that were described in the male antennal lobe of $M$. sexta in an earlier study (Huetteroth and Schachtner, 2005). Anterior in the antennal lobes we 
TABLE 1. Volume of Neuropil Structure in the Female and Male Standard Brain of Manduca sexta $(n=12)$

\begin{tabular}{|c|c|c|c|c|c|c|c|}
\hline Structure & & $\begin{array}{l}\text { Mean volume } \\
{\left[\mu \mathrm{m}^{3}\right]}\end{array}$ & $\begin{array}{c}\text { Rel. vol } \\
\text { [\%] }\end{array}$ & $\begin{array}{c}\mathrm{SD} \\
{\left[\mu \mathrm{m}^{3}\right]}\end{array}$ & $\begin{array}{c}\text { Rel. SD } \\
\text { [\%] }\end{array}$ & $\mathrm{SE}\left[\mu \mathrm{m}^{3}\right]$ & $\begin{array}{c}\text { Rel. SE } \\
\text { [\%] }\end{array}$ \\
\hline Unspecified neuropil & $\begin{array}{l}+ \\
\delta\end{array}$ & $\begin{array}{l}3.66 \times 10^{8} \\
2.71 \times 10^{8}\end{array}$ & $\begin{array}{l}31.559 \\
30.616\end{array}$ & $\begin{array}{l}4.89 \times 10^{7} \\
5.42 \times 10^{7}\end{array}$ & $\begin{array}{l}13.37 \\
20.04\end{array}$ & $\begin{array}{l}1.41 \times 10^{7} \\
1.56 \times 10^{7}\end{array}$ & $\begin{array}{l}3.86 \\
5.78\end{array}$ \\
\hline Lamina $^{1}$ (right) & $\begin{array}{l}q \\
\delta\end{array}$ & $\begin{array}{l}1.14 \times 10^{8} \\
9.52 \times 10^{7}\end{array}$ & $\begin{array}{c}9.814 \\
10.781\end{array}$ & $\begin{array}{l}6.88 \times 10^{6} \\
2.33 \times 10^{7}\end{array}$ & $\begin{array}{c}6.05 \\
24.49\end{array}$ & $\begin{array}{l}1.98 \times 10^{6} \\
8.24 \times 10^{6}\end{array}$ & $\begin{array}{l}1.75 \\
8.66\end{array}$ \\
\hline Lamina $^{1}$ (left) & $\begin{array}{l}q \\
0\end{array}$ & $\begin{array}{l}1.14 \times 10^{8} \\
8.78 \times 10^{7}\end{array}$ & $\begin{array}{l}9.832 \\
9.942\end{array}$ & $\begin{array}{l}7.61 \times 10^{6} \\
2.19 \times 10^{7}\end{array}$ & $\begin{array}{c}6.68 \\
25.03\end{array}$ & $\begin{array}{l}2.19 \times 10^{6} \\
7.77 \times 10^{6}\end{array}$ & $\begin{array}{l}1.93 \\
8.85\end{array}$ \\
\hline Medulla (right) & $\begin{array}{l}q \\
\delta\end{array}$ & $\begin{array}{l}1.59 \times 10^{8} \\
1.20 \times 10^{8}\end{array}$ & $\begin{array}{l}13.738 \\
13.602\end{array}$ & $\begin{array}{l}1.74 \times 10^{7} \\
1.99 \times 10^{7}\end{array}$ & $\begin{array}{l}10.95 \\
16.55\end{array}$ & $\begin{array}{l}5.03 \times 10^{6} \\
5.47 \times 10^{6}\end{array}$ & $\begin{array}{l}3.16 \\
4.78\end{array}$ \\
\hline Medulla (left) & $\begin{array}{l}q \\
\text { o }\end{array}$ & $\begin{array}{l}1.62 \times 10^{8} \\
1.19 \times 10^{8}\end{array}$ & $\begin{array}{l}13.953 \\
13.525\end{array}$ & $\begin{array}{l}1.37 \times 10^{7} \\
1.95 \times 10^{7}\end{array}$ & $\begin{array}{c}8.48 \\
16.40\end{array}$ & $\begin{array}{l}3.96 \times 10^{6} \\
5.66 \times 10^{6}\end{array}$ & $\begin{array}{l}2.45 \\
4.73\end{array}$ \\
\hline Outer Lobula (right) & $\begin{array}{l}q \\
\delta\end{array}$ & $\begin{array}{l}1.81 \times 10^{7} \\
1.37 \times 10^{7}\end{array}$ & $\begin{array}{l}1.566 \\
1.554\end{array}$ & $\begin{array}{l}1.54 \times 10^{6} \\
2.90 \times 10^{6}\end{array}$ & $\begin{array}{c}8.52 \\
21.19\end{array}$ & $\begin{array}{l}4.46 \times 10^{5} \\
8.39 \times 10^{5}\end{array}$ & $\begin{array}{l}2.46 \\
6.12\end{array}$ \\
\hline Outer Lobula (left) & $\begin{array}{l}q \\
0\end{array}$ & $\begin{array}{l}1.87 \times 10^{7} \\
1.37 \times 10^{7}\end{array}$ & $\begin{array}{l}1.619 \\
1.556\end{array}$ & $\begin{array}{l}2.23 \times 10^{6} \\
2.51 \times 10^{6}\end{array}$ & $\begin{array}{l}11.89 \\
18.32\end{array}$ & $\begin{array}{l}6.44 \times 10^{5} \\
7.27 \times 10^{5}\end{array}$ & $\begin{array}{l}3.43 \\
5.29\end{array}$ \\
\hline Inner Lobula (right) & $\begin{array}{l}q \\
0\end{array}$ & $\begin{array}{l}1.75 \times 10^{7} \\
1.35 \times 10^{7}\end{array}$ & $\begin{array}{l}1.513 \\
1.532\end{array}$ & $\begin{array}{l}3.26 \times 10^{6} \\
2.55 \times 10^{6}\end{array}$ & $\begin{array}{l}18.61 \\
18.84\end{array}$ & $\begin{array}{l}9.43 \times 10^{5} \\
7.36 \times 10^{5}\end{array}$ & $\begin{array}{l}5.37 \\
5.44\end{array}$ \\
\hline Inner Lobula (left) & $\begin{array}{l}q \\
\text { o }\end{array}$ & $\begin{array}{l}1.76 \times 10^{7} \\
1.31 \times 10^{7}\end{array}$ & $\begin{array}{l}1.520 \\
1.486\end{array}$ & $\begin{array}{l}3.04 \times 10^{6} \\
2.79 \times 10^{6}\end{array}$ & $\begin{array}{l}17.30 \\
21.28\end{array}$ & $\begin{array}{l}8.80 \times 10^{5} \\
8.07 \times 10^{5}\end{array}$ & $\begin{array}{l}4.99 \\
6.14\end{array}$ \\
\hline Lobula plate (right) & $\begin{array}{l}+ \\
0 \\
0\end{array}$ & $\begin{array}{l}2.44 \times 10^{7} \\
1.75 \times 10^{7}\end{array}$ & $\begin{array}{l}2.217 \\
1.982\end{array}$ & $\begin{array}{l}2.00 \times 10^{6} \\
2.90 \times 10^{6}\end{array}$ & $\begin{array}{c}8.18 \\
16.60\end{array}$ & $\begin{array}{l}5.76 \times 10^{\prime 5} \\
8.39 \times 10^{5}\end{array}$ & $\begin{array}{l}4.02 \\
4.79\end{array}$ \\
\hline Lobula plate (left) & $\begin{array}{l}\text { P } \\
0\end{array}$ & $\begin{array}{l}2.45 \times 10^{7} \\
1.73 \times 10^{7}\end{array}$ & $\begin{array}{l}2.186 \\
1.960\end{array}$ & $\begin{array}{l}2.96 \times 10^{6} \\
2.08 \times 10^{6}\end{array}$ & $\begin{array}{l}12.05 \\
12.02\end{array}$ & $\begin{array}{l}8.53 \times 10^{5} \\
6.01 \times 10^{5}\end{array}$ & $\begin{array}{l}4.58 \\
3.47\end{array}$ \\
\hline Accessory medulla (right) & $\begin{array}{l}q \\
\delta\end{array}$ & $\begin{array}{l}2.95 \times 10^{5} \\
2.76 \times 10^{5}\end{array}$ & $\begin{array}{l}0.025 \\
0.031\end{array}$ & $\begin{array}{l}6.33 \times 10^{4} \\
4.22 \times 10^{4}\end{array}$ & $\begin{array}{l}21.47 \\
15.32\end{array}$ & $\begin{array}{l}1.82 \times 10^{4} \\
1.22 \times 10^{4}\end{array}$ & $\begin{array}{l}6.20 \\
4.42\end{array}$ \\
\hline Accessory medulla (left) & $\begin{array}{l}q \\
\delta\end{array}$ & $\begin{array}{l}2.94 \times 10^{5} \\
2.78 \times 10^{5}\end{array}$ & $\begin{array}{l}0.025 \\
0.031\end{array}$ & $\begin{array}{l}5.90 \times 10^{4} \\
4.51 \times 10^{4}\end{array}$ & $\begin{array}{l}20.11 \\
16.21\end{array}$ & $\begin{array}{l}1.70 \times 10^{4} \\
1.30 \times 10^{4}\end{array}$ & $\begin{array}{l}5.81 \\
4.68\end{array}$ \\
\hline Pedunculus (right) & $\begin{array}{l}\text { } \\
\delta\end{array}$ & $\begin{array}{l}8.54 \times 10^{6} \\
6.40 \times 10^{6}\end{array}$ & $\begin{array}{l}0.737 \\
0.725\end{array}$ & $\begin{array}{l}9.88 \times 10^{5} \\
1.04 \times 10^{6}\end{array}$ & $\begin{array}{l}11.57 \\
16.27\end{array}$ & $\begin{array}{l}2.85 \times 10^{5} \\
3.01 \times 10^{5}\end{array}$ & $\begin{array}{l}3.34 \\
4.70\end{array}$ \\
\hline Pedunculus (left) & $\begin{array}{l}q \\
\delta\end{array}$ & $\begin{array}{l}8.28 \times 10^{6} \\
6.11 \times 10^{6}\end{array}$ & $\begin{array}{l}0.715 \\
0.692\end{array}$ & $\begin{array}{l}1.13 \times 10^{6} \\
1.05 \times 10^{6}\end{array}$ & $\begin{array}{l}13.65 \\
17.12\end{array}$ & $\begin{array}{l}3.27 \times 10^{5} \\
3.02 \times 10^{5}\end{array}$ & $\begin{array}{l}3.94 \\
4.94\end{array}$ \\
\hline Caly $\times$ (right) & $\begin{array}{l}q \\
0\end{array}$ & $\begin{array}{l}1.07 \times 10^{7} \\
8.00 \times 10^{6}\end{array}$ & $\begin{array}{l}0.921 \\
0.906\end{array}$ & $\begin{array}{l}1.19 \times 10^{6} \\
1.19 \times 10^{6}\end{array}$ & $\begin{array}{l}11.12 \\
14.83\end{array}$ & $\begin{array}{l}3.43 \times 10^{5} \\
3.43 \times 10^{5}\end{array}$ & $\begin{array}{l}3.21 \\
4.28\end{array}$ \\
\hline Caly× (left) & $\begin{array}{l}q \\
\sigma\end{array}$ & $\begin{array}{l}1.07 \times 10^{7} \\
7.77 \times 10^{6}\end{array}$ & $\begin{array}{l}0.926 \\
0.879\end{array}$ & $\begin{array}{l}1.26 \times 10^{6} \\
1.09 \times 10^{6}\end{array}$ & $\begin{array}{l}11.75 \\
14.03\end{array}$ & $\begin{array}{l}3.64 \times 10^{5} \\
3.15 \times 10^{5}\end{array}$ & $\begin{array}{l}3.39 \\
4.05\end{array}$ \\
\hline Central body upper unit & $\begin{array}{l}+ \\
\delta\end{array}$ & $\begin{array}{l}3.76 \times 10^{6} \\
2.76 \times 10^{6}\end{array}$ & $\begin{array}{l}0.324 \\
0.313\end{array}$ & $\begin{array}{l}4.91 \times 10^{5} \\
4.50 \times 10^{5}\end{array}$ & $\begin{array}{l}13.07 \\
16.31\end{array}$ & $\begin{array}{l}1.42 \times 10^{5} \\
1.30 \times 10^{5}\end{array}$ & $\begin{array}{l}3.77 \\
4.71\end{array}$ \\
\hline Central body lower unit & $\begin{array}{l}\text { P } \\
0\end{array}$ & $\begin{array}{l}1.30 \times 10^{6} \\
1.01 \times 10^{6}\end{array}$ & $\begin{array}{l}0.112 \\
0.114\end{array}$ & $\begin{array}{l}2.45 \times 10^{5} \\
2.35 \times 10^{5}\end{array}$ & $\begin{array}{l}18.91 \\
23.33\end{array}$ & $\begin{array}{l}7.08 \times 10^{4} \\
6.78 \times 10^{4}\end{array}$ & $\begin{array}{l}5.46 \\
6.73\end{array}$ \\
\hline Protocerebral bridge (right) & $\begin{array}{l}q \\
\delta\end{array}$ & $\begin{array}{l}4.09 \times 10^{5} \\
3.29 \times 10^{5}\end{array}$ & $\begin{array}{l}0.035 \\
0.037\end{array}$ & $\begin{array}{l}6.05 \times 10^{4} \\
5.77 \times 10^{4}\end{array}$ & $\begin{array}{l}14.81 \\
17.56\end{array}$ & $\begin{array}{l}1.75 \times 10^{4} \\
1.67 \times 10^{4}\end{array}$ & $\begin{array}{l}4.27 \\
5.07\end{array}$ \\
\hline Protocerebral bridge (left) & $\begin{array}{l}q \\
0 \\
0\end{array}$ & $\begin{array}{l}4.20 \times 10^{5} \\
3.15 \times 10^{5}\end{array}$ & $\begin{array}{l}0.036 \\
0.036\end{array}$ & $\begin{array}{l}5.94 \times 10^{4} \\
5.70 \times 10^{4}\end{array}$ & $\begin{array}{l}14.15 \\
18.08\end{array}$ & $\begin{array}{l}1.71 \times 10^{4} \\
1.65 \times 10^{4}\end{array}$ & $\begin{array}{l}4.09 \\
5.22\end{array}$ \\
\hline Nodulus (right) & $\begin{array}{l}+ \\
\delta\end{array}$ & $\begin{array}{l}1.13 \times 10^{5} \\
8.46 \times 10^{4}\end{array}$ & $\begin{array}{l}0.010 \\
0.010\end{array}$ & $\begin{array}{l}1.57 \times 10^{4} \\
1.88 \times 10^{4}\end{array}$ & $\begin{array}{l}13.90 \\
22.25\end{array}$ & $\begin{array}{l}4.54 \times 10^{3} \\
5.44 \times 10^{3}\end{array}$ & $\begin{array}{l}4.01 \\
6.42\end{array}$ \\
\hline Nodulus (left) & $\begin{array}{l}q \\
\delta\end{array}$ & $\begin{array}{l}1.15 \times 10^{5} \\
8.05 \times 10^{4}\end{array}$ & $\begin{array}{l}0.010 \\
0.009\end{array}$ & $\begin{array}{l}2.19 \times 10^{4} \\
1.41 \times 10^{4}\end{array}$ & $\begin{array}{l}19.02 \\
17.48\end{array}$ & $\begin{array}{l}6.33 \times 10^{3} \\
4.06 \times 10^{3}\end{array}$ & $\begin{array}{l}5.49 \\
5.05\end{array}$ \\
\hline Antennal lobe (right) & $\begin{array}{l}q \\
0\end{array}$ & $\begin{array}{l}3.62 \times 10^{7} \\
3.24 \times 10^{7}\end{array}$ & $\begin{array}{l}3.126 \\
3.673\end{array}$ & $\begin{array}{l}3.20 \times 10^{6} \\
6.13 \times 10^{6}\end{array}$ & $\begin{array}{c}8.82 \\
18.89\end{array}$ & $\begin{array}{l}9.23 \times 10^{5} \\
1.77 \times 10^{6}\end{array}$ & $\begin{array}{l}2.55 \\
5.45\end{array}$ \\
\hline Antennal lobe (left) & $\begin{array}{l}q \\
0\end{array}$ & $\begin{array}{l}3.54 \times 10^{7} \\
3.16 \times 10^{7}\end{array}$ & $\begin{array}{l}3.055 \\
3.578\end{array}$ & $\begin{array}{l}3.78 \times 10^{6} \\
6.14 \times 10^{6}\end{array}$ & $\begin{array}{l}10.68 \\
19.44\end{array}$ & $\begin{array}{l}1.09 \times 10^{6} \\
1.77 \times 10^{6}\end{array}$ & $\begin{array}{l}3.08 \\
5.61\end{array}$ \\
\hline $\begin{array}{l}\text { Anterior optic tubercle upper unit } \\
\text { (right) }\end{array}$ & $\begin{array}{l}q \\
\delta\end{array}$ & $\begin{array}{l}1.74 \times 10^{6} \\
1.38 \times 10^{6}\end{array}$ & $\begin{array}{l}0.150 \\
0.157\end{array}$ & $\begin{array}{l}2.79 \times 10^{5} \\
2.60 \times 10^{5}\end{array}$ & $\begin{array}{l}16.02 \\
18.76\end{array}$ & $\begin{array}{l}8.06 \times 10^{4} \\
7.48 \times 10^{4}\end{array}$ & $\begin{array}{l}4.63 \\
5.42\end{array}$ \\
\hline $\begin{array}{l}\text { Anterior optic tubercle upper unit } \\
\text { (left) }\end{array}$ & $\begin{array}{l}\stackrel{+}{+} \\
\delta\end{array}$ & $\begin{array}{l}1.73 \times 10^{6} \\
1.50 \times 10^{6}\end{array}$ & $\begin{array}{l}0.149 \\
0.170\end{array}$ & $\begin{array}{l}2.15 \times 10^{5} \\
4.63 \times 10^{5}\end{array}$ & $\begin{array}{l}12.44 \\
30.80\end{array}$ & $\begin{array}{l}6.20 \times 10^{4} \\
1.34 \times 10^{5}\end{array}$ & $\begin{array}{l}3.59 \\
8.89\end{array}$ \\
\hline $\begin{array}{l}\text { Anterior optic tubercle lower unit } \\
\text { (right) }\end{array}$ & $\begin{array}{l}q \\
\delta\end{array}$ & $\begin{array}{l}2.50 \times 10^{5} \\
1.74 \times 10^{5}\end{array}$ & $\begin{array}{l}0.022 \\
0.020\end{array}$ & $\begin{array}{l}5.05 \times 10^{4} \\
4.23 \times 10^{4}\end{array}$ & $\begin{array}{l}20.22 \\
24.29\end{array}$ & $\begin{array}{l}1.46 \times 10^{4} \\
1.22 \times 10^{4}\end{array}$ & $\begin{array}{l}5.84 \\
7.01\end{array}$ \\
\hline $\begin{array}{l}\text { Anterior optic tubercle lower unit } \\
\text { (left) }\end{array}$ & $\begin{array}{l}q \\
0\end{array}$ & $\begin{array}{l}2.68 \times 10^{5} \\
1.76 \times 10^{5}\end{array}$ & $\begin{array}{l}0.023 \\
0.019\end{array}$ & $\begin{array}{l}7.33 \times 10^{4} \\
4.17 \times 10^{4}\end{array}$ & $\begin{array}{l}27.39 \\
25.36\end{array}$ & $\begin{array}{l}2.12 \times 10^{4} \\
1.20 \times 10^{4}\end{array}$ & $\begin{array}{l}7.91 \\
7.32\end{array}$ \\
\hline $\begin{array}{l}\text { Anterior optic tubercle nodular unit } \\
\text { (right) }\end{array}$ & $\begin{array}{l}+ \\
\delta\end{array}$ & $\begin{array}{l}4.74 \times 10^{5} \\
2.76 \times 10^{5}\end{array}$ & $\begin{array}{l}0.041 \\
0.031\end{array}$ & $\begin{array}{l}7.46 \times 10^{4} \\
8.43 \times 10^{4}\end{array}$ & $\begin{array}{l}15.73 \\
30.48\end{array}$ & $\begin{array}{l}2.15 \times 10^{4} \\
2.43 \times 10^{4}\end{array}$ & $\begin{array}{l}4.54 \\
8.80\end{array}$ \\
\hline $\begin{array}{l}\text { Anterior optic tubercle nodular unit } \\
\text { (left) }\end{array}$ & $\stackrel{\circ}{0}$ & $\begin{array}{l}4.51 \times 10^{5} \\
2.97 \times 10^{5}\end{array}$ & $\begin{array}{l}0.039 \\
0.034\end{array}$ & $\begin{array}{l}9.17 \times 10^{4} \\
7.36 \times 10^{4}\end{array}$ & $\begin{array}{l}20.35 \\
24.73\end{array}$ & $\begin{array}{l}2.65 \times 10^{4} \\
2.13 \times 10^{4}\end{array}$ & $\begin{array}{l}5.87 \\
7.14\end{array}$ \\
\hline
\end{tabular}

Mean volume, relative volume (Rel. vol), standard deviation (SD), relative standard deviation (Rel. SD), standard error (SE), and relative standard error (Rel. SE) of all 30 segmented brain areas plus the unspecified neuropil in the female $(n=12)$ and male $(n=12)$ standard brain of $M$. sexta.

${ }^{1}$ The mean volume of the male lamina based on eight individuals.

reconstructed the glomeruli disc and discbase, also known in the literature as mortar and pestle (Lipscomb and Tolbert, 2006; Fig. 7B,B'), and possibly homologous to flower and flowerbase in the silkmoth Bombyx mori (Terada et al., 2003;
Kazawa et al., 2009). Most ventrally is the labial pit organ glomerulus (LPOG), the only glomerulus not innervated by the antennal nerve but by sensory neurons from the labial palps (Kent et al., 1986; Fig. 7C,C'). This glomerulus received recent 

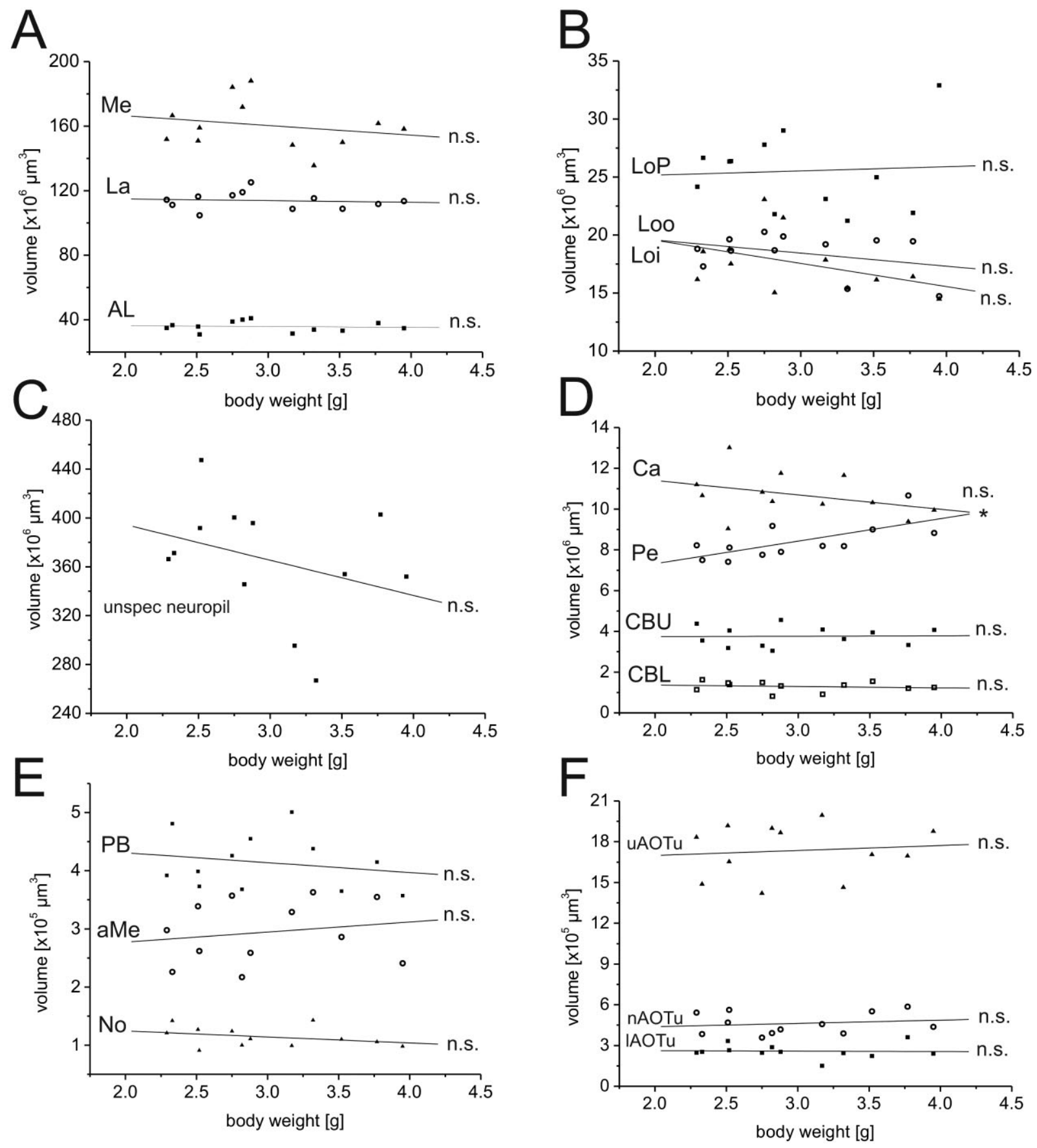

Figure 5.

Relation between body weight and neuropil volume in the female brain. Regression lines indicate no significant correspondence between both parameters except for the pedunculi. A: $\mathrm{Me}=$ medullae; $\mathrm{La}=$ laminae; $\mathrm{AL}=$ antennal lobes. $\mathrm{B}$ : LoP $=$ lobula plates; Loi, Loo $=$ inner and outer lobulae. C: unspec neuropil = "unspecified neuropil." D: $\mathrm{Ca}=$ calyces; $\mathrm{Pe}=$ pedunculi; $\mathrm{CBU}, \mathrm{CBL}=$ upper and lower unit of central body. $\mathrm{E}: \mathrm{PB}=$ protocerebral bridges; aMe = accessory medullae; No = noduli. F: uAOTu, IAOTu, nAOTu = upper, lower and nodular units of anterior optic tubercles; n.s. $=$ not significant, ${ }^{*} P<0.05$.

attention as being responsible for detecting $\mathrm{CO}_{2}$ (Guerenstein et al., 2004; Guerenstein and Hildebrand, 2008). Further ventral glomeruli are the club, base, and cap (Fig. 7C,C'). Right posterior to the sex-related glomeruli we labeled the largest of the "ordinary" glomeruli, G20 (Fig. 7D,D'). Figure 7B'-D' shows frontal optical slices according to the planes named in Figure $7 A$ in an individual antennal lobe in the right hemisphere of the brain. In Figure 7B-D we show the labels of the identified glomeruli on the same image. For clarification, we included the $\mathrm{AL}$ outline, which surrounds all $63 \pm 1$ glomeruli plus the 

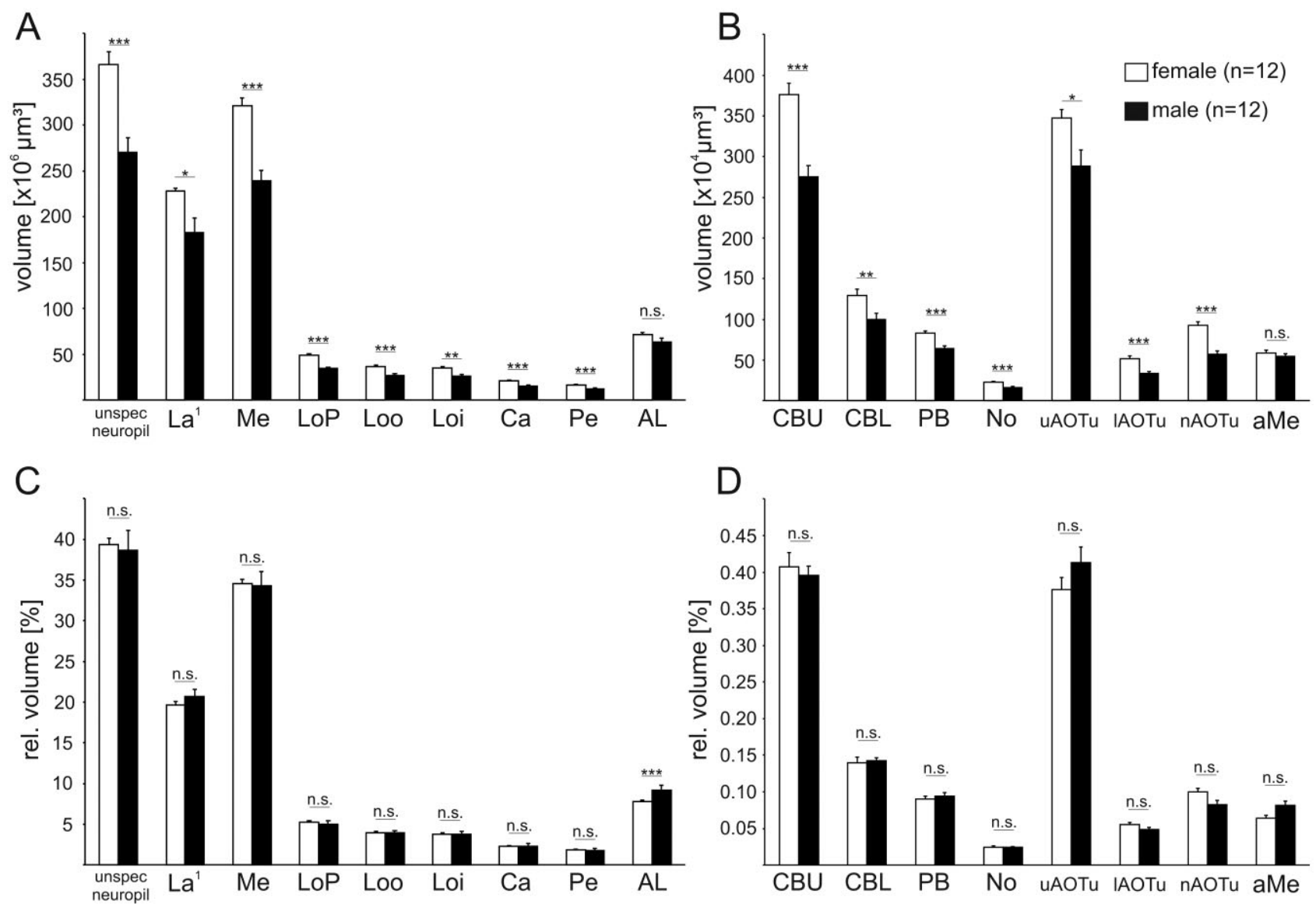

Figure 6.

Comparison of neuropil volumes between female (white) and male (black) brains. A,B: All female brain neuropil volumes are significantly larger than the corresponding male neuropil volumes apart from the antennal lobes (AL) and the accessory medullae (aMe). C,D: After normalizing all neuropil volumes to overall neuropil volume, almost all showed no significant differences apart from the same two neuropils. The accessory medullae (aMe) exhibited weakly significant differences, whereas the larger antennal lobes of males became strongly significant. (Bars: standard error; ${ }^{\star \star \star} P<0.001,{ }^{\star \star} P<0.01,{ }^{\star} P<0.05$, n.s. not significant.) ${ }^{1}$ The volume of male laminae is based on eight individuals.

lateral (LC), median (MC), and anterior cell group (AC) (Fig. 7A). Besides the identified 10 glomeruli the remaining glomeruli are shown in gray transparent in the reconstruction (Fig. 7A').

Supplementary material 7 gives mean volumes, standard deviation, and standard error of the absolute and relative volumes of the six identified "ordinary" glomeruli, the LPOG, and the three sex-related glomeruli of the 11 antennal lobes. The weight of the 11 animals averages $2.92 \pm 0.61 \mathrm{~g}$, representative of the mean weight of all measured females. All female glomerular volumes (Fig. 8, white bars) were compared to their corresponding male values (black bars) of freshly eclosed male brains (Fig. 8; Rospars and Hildebrand, 2000; Huetteroth and Schachtner, 2005). Not surprisingly, the volume of the male sex-related glomeruli cumulus and toroid are about 5.8-fold bigger than the homologous glomeruli mLFG and ILFG in the female antennal lobe. Taken together, the volumes of all three sex-related glomeruli of the male antennal lobe are 5.1-fold larger than the volumes of the three femalespecific glomeruli. The only nonsignificant exception is the third sex-specific glomerulus, the horseshoe/SFG (Fig. 8). All remaining six normal female glomeruli and the LPOG exceed their male counterparts significantly in absolute volume, sim- ilar to the protocerebral brain neuropils. After taking this known size difference into account and correcting female glomerulus volumes by the factor 0.76 (gray bars, see previous section), none of the normal glomeruli remains significantly larger in females. Even more pronounced than before, the three male sex-specific glomeruli underline their bigger size, leaving them as the only real anisometric volume dimorphism found in $M$. sexta brain neuropils.

\section{DISCUSSION}

To compare neuropilar volumes between sexes we produced a female and male standard brain based on 12 freshly eclosed female and male $M$. sexta. We showed that after compensating volumes for general isometric size dimorphism, an anisometric brain difference between sexes is restricted to the three well-described sex-specific glomeruli in the antennal lobe, and neither reflected in higher brain centers nor in other identified homologous glomeruli of the AL. Additionally, we provided an anatomical reference and volumetric standard of 10 selected female olfactory glomeruli that are homologous to 10 male glomeruli described earlier (Huetteroth and Schacht- 

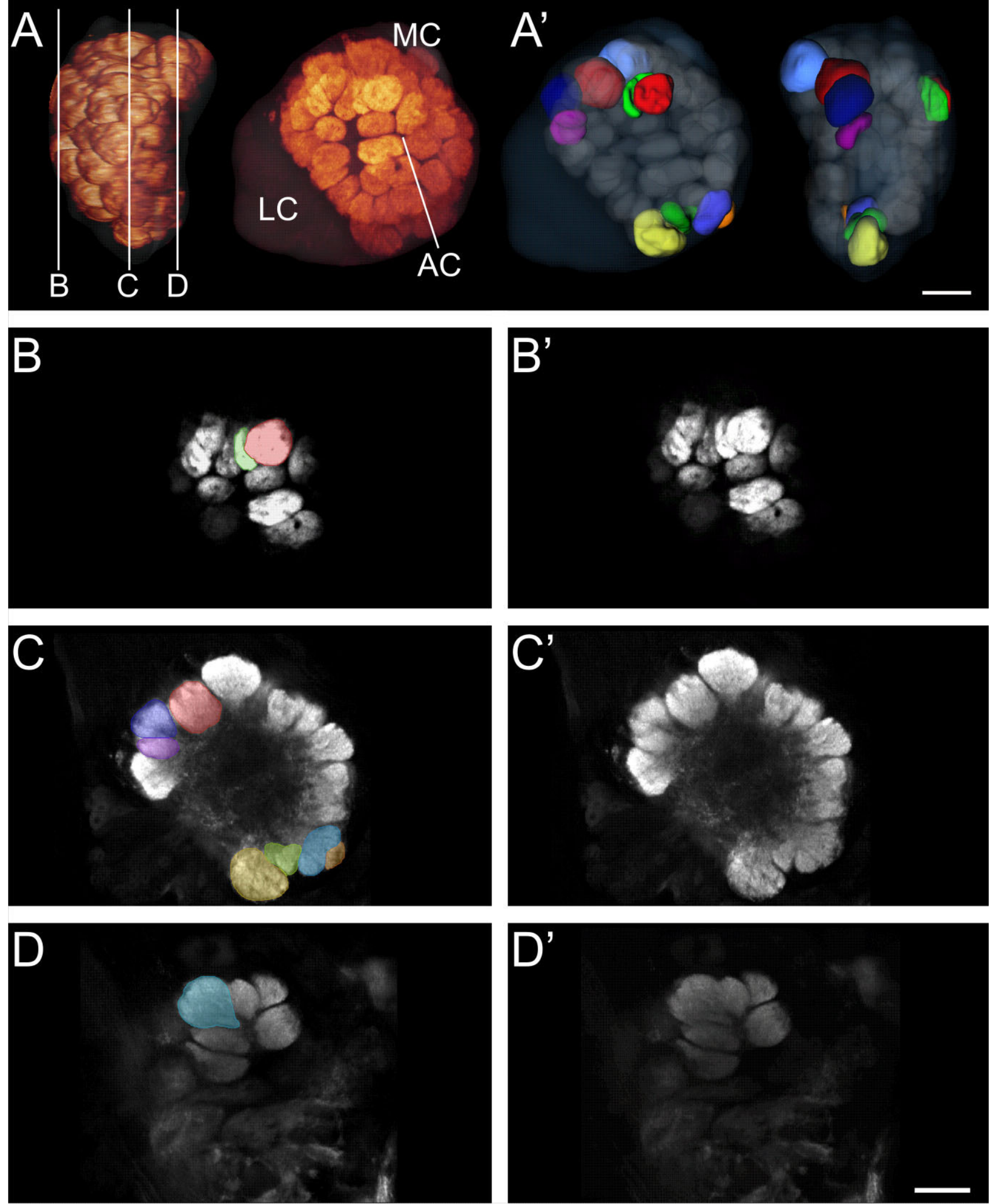

Figure 7.

Antennal lobe of a female M. sexta brain. A: Median and anterior view of a right antennal lobe after volume rendering of synapsin-immunoreactivity. A': Anterior and lateral view of 3D-reconstructed glomeruli of the same antennal lobe. In the anterior view of the volume rendering the approximate location of the lateral (LC), median (MC), and anterior cell group (AC) is denoted. The vertical bars in the median view display section levels of B-D and B'-D', respectively. Ten identified glomeruli in the 3D reconstruction are colored according to 10 homologous male glomeruli (see below; Huetteroth and Schachtner, 2005). Other glomeruli are displayed in transparent gray; the displayed outline of the AL is shown in transparent blue. B-D: Axial slices through the antennal lobe at different levels. B: Two of the most anteriorly located glomeruli are disc (bright red) and discbase (green). C: Axial slice through the center of the antennal lobe containing the labial pit organ glomerulus (LPOG; yellow), club (green), base (blue), and cap (orange). Additionally, the sex-specific glomeruli of the female antennal lobe are visible, the small (SFG; purple), medial large (mLFG; dark red), and lateral large female glomerulus (ILFG; dark blue). D: Posterior part of the antennal lobe displaying G20 (bright blue), the largest of the "ordinary" glomeruli. B'-D': Confocal slices through the antennal lobe corresponding to B-D. Scale bars $=100 \mu \mathrm{m}$. 


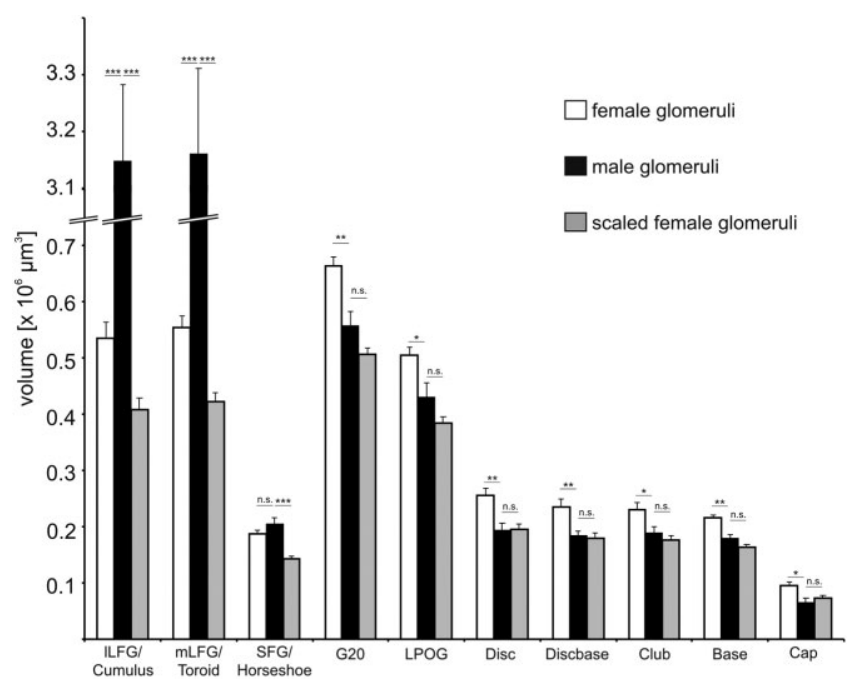

Figure 8.

Volume comparison between the 10 identified glomeruli of the female (white; $n=11$ ) and the male antennal lobe (black; $n=16$; Huetteroth and Schachtner, 2005) of $M$. sexta. All "ordinary" glomeruli and the LPOG are significantly larger in females $(P<0.05)$. The three sexspecific glomeruli of the male antennal lobe (cumulus, toroid, and horseshoe) are together $\approx 5.75$-fold larger than the corresponding homologous glomeruli of the female antennal lobe (lateral and median large female glomerulus, ILFG and mLFG, and small female glomerulus, SFG). After normalizing female glomerulus volume by a factor of 0.76 (see Results), all "normal" glomeruli and the LPOG exhibit similar volumes to their male counterparts. Only the three sex-dimorphic glomeruli show highly significant larger volumes in males. (Bars: standard error; ${ }^{\star \star \star} P<0.001$; ${ }^{\star \star} P<0.01$; ${ }^{\star} P<0.05$; n.s., not significant.)

ner, 2005). Compared to existing insect standard brains, the $M$. sexta standard poses the largest brain so far with respect to absolute size.

\section{Standard brain generation}

To obtain a standard insect brain, two methods have been established: the virtual insect brain (VIB) protocol, as used for the fruit fly (Rein et al., 2002; Jenett et al., 2006), and the iterative shape averaging (ISA) method, as used for the honeybee (Rohlfing et al., 2004; Brandt et al., 2005). The VIB protocol was primarily developed to compare brain area measurements, such as between wildtype and genetically manipulated Drosophila, while the ISA method aims to generate a synthetic but realistic standard brain, into which single reconstructed neurons from various individuals could be mapped. The VIB script keeps neuropil volumes unchanged, while the ISA method, in contrast, averages anatomical differences on the cost of volume accuracy (Ku $\beta$ et al., 2007; Kurylas et al., 2008). Both methods require an initial reference or template brain for alignment. While the visualization of the standardized brain areas using the VIB protocol is clearly biased toward this template, the ISA method is thought to be independent of the choice of the template (Guimond et al., 2000; Brandt et al., 2005), with the notable exceptions of orientation and scale. During affine registration in the ISA method, all brains are resized using anisotropic scaling to match the size of the template brain. Thus, the resulting standard volumes of the brain areas generated by the ISA method depend on the choice of the template brain (Rohlfing et al., 2001; Rohlfing, pers. commun.). Therefore, we decided to use the VIB protocol for standardization, since we primarily wanted to compare volumes of neuropils and did not aim for registration of reconstructed neurons (Rø et al., 2007; Kurylas et al., 2008). Given that both methods are established in our laboratory, a female and a male standard brain calculated by the ISA method could be computed on request.

It has to be noted that our wholemount specimens, like all immunohistochemical preparations, are subjected to considerable tissue shrinking (Bucher et al., 2000; Ott, 2008). Therefore, absolute sizes are probably underestimated and make most sense in relative comparisons, i.e., comparisons might only be useful between brains after similar histological treatment. In a previous work we showed the utility of 3D reconstructions to quantify adult plasticity in the male antennal lobe (Huetteroth and Schachtner, 2005). Since we carefully checked for animal age, the female and male standard brain will serve as a reference in future quantitative studies using pharmacological or behavioral approaches. Currently we are including the standard brain into a developmental framework, with volumetric data on neuropil growth during the pupal stages.

\section{Brain and body size correlation}

The 12 female and 12 male brains analyzed cover almost the whole span of weights encountered in a set of 74 females and 60 males. Thus, the allometric comparisons of neuropil volumes might sufficiently represent the natural variance in animal size (Fig. 3). Despite a weight variance of about 2-fold, we found, with the exception of the female MB pedunculi, neither in female nor male brains an allometric relationship between brain size and body weight (Fig. 5, Suppl. 5). As a general rule, within the same taxon or animal group, larger animals typically have larger brains (e.g., Gould, 1966, 1975; Harvey, 1988; Wehner et al., 2007). Does this correlation also apply to the same species? In hymenopteran insect species, labor and size polymorphism is well known (e.g., Wilson, 1971; Garofalo, 1978; Winston, 1987; Hölldobler and Wilson, 1990, 2008). Studies on the bumblebee (Bombus impatiens) and several ant species revealed a positive correlation between body weight (which tightly correlates with brain width) and brain size (Mares et al., 2005; Wehner et al., 2007). In contrast, in honeybees, which show a similar modest weight variance as our Manduca (about 2-fold), also no correlation between body weight and brain size could be found (Mares et al., 2005).

The only allometric relation we found were the MB pedunculi in the female brain. We do not want to stress this exception, since increased $n$ size might have eliminated this finding. Remarkably, it was also the pedunculi in honeybees that showed exceptional allometric behavior (Mares et al., 2005).

\section{Brain neuropil comparison between sexes}

Almost all neuropilar volumes in females are larger than their male counterparts (Fig. 6A,B). The two exceptions are the aMe and the AL, which showed similar volumes in both sexes. After normalization to overall neuropilar volume, both aMe $(P<0.05)$ and $\mathrm{AL}(P<0.001)$ were significantly larger in males compared to females, while all other neuropils showed no significant differences (Fig. 6C,D). Because small neuropils 
like the aMe are especially prone to measuring errors and small labeling differences have large effects on overall volume (Julian and Gronenberg, 2002; Kurylas et al., 2008), we do not want to overemphasize the difference in the aMe. In contrast, the relative difference in the antennal lobe neuropil volume between males and females became highly significant (Fig. $6 \mathrm{C})$. In summary, these results strongly imply no anisometric neuropilar sexual dimorphism in the $M$. sexta brain apart from the antennal lobes, or better, the sex-specific glomeruli in the antennal lobes (see below).

This was not self-evident; a dimorphic correlate of the antennal lobe might have been present in one of the target regions of $\mathrm{AL}$ output neurons, the calyces. According to Homberg et al. (1988) males contain $\approx 30$ projection neurons more than females, which project to special areas in the calyces. Thus, it could have been possible to detect a representation of the MGC in downstream neuropils on a volumetric level. Pearson (1971) states by citing Hanström (1928) that the size of the AL and the calyx in moths are correlated. The author explains this observation with the massive antennocerebral tracts which serve as main input to the calyces, thus strongly interlinking both neuropils. Although this sounds plausible, we did not find a significant correlation between AL and calyx volumes (data not shown). Thirty neurons comprise $\approx 15 \%$ of the projection neurons housed in the median cell group projecting through the inner antennocerebral tract to the calyx (Homberg et al., 1988). As the individual differences of calyx volumes reflected by the standard deviation are in both sexes between $11 \%$ and $15 \%$, a sex-specific difference may be confined to the individual volume variations, and is thus not recognized by volume comparisons as performed in this study. It has to be noted that another major target area of antennal lobe projection neurons, the inferior lateral protocerebrum or lateral horn, exhibits no clear neuropilar boundaries. Therefore, we refrained from labeling this region separately and included its volume in the "unspecified neuropil." It is known from the silkmoth Bombyx mori that projection neurons originating in the MGC are targeting different areas in the inferior lateral protocerebrum (Kanzaki et al., 2003). It can be assumed that target areas innervated by projection neurons coming from ordinary glomeruli also have their distinct location, as is the case in Drosophila (Jefferis et al., 2007).

What about sexual dimorphism in the optic lobes? In a recent work a sexual dimorphic innervation of the lobula plate was described in hoverflies (Nordström et al., 2008), and a previous work describes male-specific neurons in fly lobulae (Strausfeld, 1991). Generally, in Dipteran species sexual dimorphic optic lobes seem to be rather the norm than the exception, although usually males exhibit more cells or more elaborate neuronal branching patterns than females (reviewed in Wehner, 1981; Zeil, 1983). Male-specific interneurons in the fly brain were shown to prevent programmed cell death by expressing fruitless, a factor being discussed as regulating sexual dimorphism in the brain (Kimura et al., 2005). In intracellular recording studies on optic lobe neurons of both sexes of $M$. sexta no sexual dimorphic arborizations were mentioned (Milde, 1993; Wicklein and Strausfeld, 2000).

\section{Antennal lobe comparison between sexes}

Anatomical sexual dimorphism in the antennal lobes has been found in several species (Schachtner et al., 2005). Usually in males, enlarged glomeruli at the entrance site of the antennal nerve are described, as shown for cockroaches (Jawlowski, 1948; Neder, 1959; Boeckh et al., 1987), bees (Arnold et al., 1984; Brockmann and Brückner, 2001), ants (Kleineidam et al., 2005; Nishikawa et al., 2008), flies (Kondoh et al., 2003), and of course moths (reviewed in Anton and Homberg, 1999; Hansson and Anton, 2000) including M. sexta (Camazine and Hildebrand, 1979; Matsumoto and Hildebrand, 1981; Schneiderman et al., 1982). These glomeruli are usually cited as macroglomerulus or, if more than one, as macroglomeruli or "macroglomerular complex" (MGC). In M. sexta, and probably all other species, these glomeruli are involved in pheromone signal processing (reviewed, e.g., in Hansson and Christensen, 1999).

Until now the only 3D reconstruction of the female antennal lobe in $M$. sexta was based on two individuals and possessed only limited information about glomerulus shape or volume (Rospars and Hildebrand, 2000). Nevertheless, this work showed for the first time the correspondence of the three sex-specific glomeruli ILFG, mLFG, and SFG, to their male counterparts, the homologous glomeruli cumulus, toroid, and horseshoe of the MGC. Physiological studies demonstrated for ILFG output neurons that they respond preferentially to stimulation with linalool, which is a volatile emitted from plants, including M. sexta host plants (King et al., 2000; Reisenman et al., 2004; but see also Hansson et al., 2003). In the current study we compared corresponding male and female glomeruli on a quantitative basis. In two previous studies male and female antennal lobes of the moths Lobesia botrana (Masante-Roca et al., 2002) and Heliothis virescens (Berg et al., 2002) were 3D-reconstructed and single glomeruli were identified; however, neither study compared glomerular volumes quantitatively.

Our volumetric sex comparisons in the AL took advantage of a previously published work on glomerular volumes of 16 ALs of freshly eclosed male animals (Huetteroth and Schachtner, 2005). We found in 10 identified glomeruli approximately the same dimorphism for the remaining brain neuropils as before; all glomeruli are significantly larger in females, apart from the three glomeruli homologous to the MGC. The MGC exceeds the combined size of homologous female glomeruli by far, paying tribute to its massive innervation by pheromone-sensitive OSNs (Lee and Strausfeld, 1990). After application of a correction factor on glomerular volumes, derived from brain neuropils in males and females, no significant difference between most male and female glomeruli could be observed (Fig. 8). The only exceptions were the sexual dimorphic glomeruli; their volume differences became even more pronounced. The six normal glomeruli and the LPOG should give a good estimate of all remaining glomeruli in the $A L$. We therefore conclude that the only anisometric volume dimorphism in $M$. sexta is limited to the primary integration center of pheromone odor information, or more specifically, to their main components bombycal or (E,Z)-10,12-hexadecadienal in the toroid and $(E, Z)-11,13$-pentadecadienal in the cumulus (Christensen and Hildebrand, 1987; Hansson et al., 1991, 2003; Heinbockel et al., 1998).

\section{Interspecies brain comparison}

The relative size of a defined brain area is closely related to its importance for the respective animal (e.g., Barton et al., 1995; Gronenberg and Hölldobler, 1999; Schoenemann, 2006). For example, in insects larger optic lobes primarily correlate 
TABLE 2. Comparison of Relative Neuropilar Volumes between Different Insect Species Obtained from Four Different Insect Orders

\begin{tabular}{|c|c|c|c|c|c|}
\hline Order & Diptera & Hymenoptera & Orthoptera & \multicolumn{2}{|c|}{ Lepidoptera } \\
\hline Species & D. melanogaster & A. mellifera & S. gregaria & \multicolumn{2}{|c|}{ M. sexta } \\
\hline Sex & q & forager & $\delta$ & 우 & $\sigma$ \\
\hline Number of individuals & 28 & 20 & 10 & 12 & 12 \\
\hline Optic lobes & $79.65 \%$ & $57.91 \%$ & $72.67 \%$ & $79.36 \%$ & $77.35 \%$ \\
\hline Antennal lobes & $9.36 \%$ & $8.53 \%$ & $9.68 \%$ & $12.86 \%$ & $15.09 \%$ \\
\hline Central body & $3.43 \%$ & $0.91 \%$ & $1.67 \%$ & $0.91 \%$ & $0.89 \%$ \\
\hline Mushroom bodies & $7.56 \%$ & $32.65 \%$ & $15.98 \%$ & $6.87 \%$ & $6.76 \%$ \\
\hline
\end{tabular}

Insect orders: Diptera (Drosophila melanogaster: Rein et al., 2002), Hymenoptera (Apis mellifera: Brandt et al., 2005), Orthoptera (Schistocerca gregaria: Kurylas et al., 2008), and Lepidoptera ( $M$. sexta, this work). We included the sex and the number of individuals that were used for respective standardization. Only neuropils which have complements in all examined animals were compared (medulla, lobula complex, lobula plate, antennal lobe, calyces, and pedunculi of the mushroom bodies, upper and lower unit of the central body).

with a larger complex eye containing more photoreceptor cells, while the volume of ALs correlates with the amount of olfactory sensory axons entering this structure. Likewise, the volumes and the organization of higher-order integration centers like the mushroom bodies correlate with the amount of multimodal sensory information they integrate and thus to the complexity of information they process (e.g., Technau, 2007; Molina and O'Donnell, 2008). Additionally, studies in several insect species demonstrated a correlation of volumes of brain areas with age, caste, sex, and experience, including primary sensory integration centers like $\mathrm{OL}$ and $\mathrm{AL}$, but also higher integration centers like the mushroom bodies (Heisenberg et al., 1995; Barth and Heisenberg, 1997; Barth et al., 1997; Sigg et al., 1997; Julian and Gronenberg, 2002; Groh et al., 2006; Technau, 2007; Molina and O'Donnell, 2008). The few existing insect standard brains can only give a limited view on the respective relative volumes of defined brain areas of these species because they provide 1) only one sex and 2) one age (D. melanogaster: 5-day-old adult females; Rein et al., 2002), or 3$)$ even a mixture of different ages ( $A$. mellifera foragers: Brandt et al., 2005; S. gregaria males: Kurylas et al., 2008). Caste or possible experience-dependent differences have also not been taken into account. Thus, a comparison between the relative volumes of the available standardized brain areas has to be judged with these prerequisites (Table 2).

Regarding the central complex, the sum of relative ellipsoid body volume and fan-shaped body volume in the fly exceed those of the upper and lower units of the central complex in locust, honeybee, and moth. The function of the central complex still remains elusive, but is probably best described as a central coordinating function in sensory and motor integration (for reviews, see Strauss, 2002; Wessnitzer and Webb, 2006; Homberg, 2008). Interestingly, $A$. mellifera and $M$. sexta showed about similar small relative central complex volumes, suggesting a less complex function than in fly and locust. In this context, it would be interesting to have comparable standardized central complex volumes of ants and migratory lepidopterans, i.e., monarch butterflies (Danaus plexippus; Reppert, 2006).

Much more pronounced than in the central complex are the differences in relative volume of the mushroom bodies. While the social honeybee by far exhibits the largest mushroom bodies, the smallest are found in M. sexta (Table 2). Mushroom bodies, generally associated with higher integration processes and learning, vary considerably in relative size in different nymphalid butterflies, without correlating to optic or antennal lobe size. Heliconius charitonius, for example, stands out as having almost four times bigger mushroom bodies than other butterflies of that family (Sivinsky, 1989).
This is attributed to its relative long life. combined with its occurrence in forested habitats with only scattered food resources, and a shared resting place with conspecifics. As discussed by the author, remembering a common resting place and good food sites might be a higher evolutionary constraint for learning ability than finding proper egg-laying sites, which does not necessarily involve memory tasks (Sivinsky, 1989). For the ant Cataglyphis, Wehner et al. (2007) discussed social interaction rather than food gathering for being responsible of bigger mushroom bodies compared to other ant species, an idea originally brought up by Alten (1910). Newborn cells might contribute to bigger mushroom bodies, as adult neurogenesis does occur in moths (Dufour and Gadenne, 2006). Despite the short lifespan of $M$. sexta and the smallest mushroom bodies in our comparison (Table 2), we cannot exclude the possibility of behavior-dependent volume changes in adults. $M$. sexta learned odors by classical conditioning (Daly and Smith, 2000; Daly et al., 2001), learning of odors and colors in free-flying animals was shown (Riffell et al., 2008; Goyret et al., 2008), age- and mating-dependent behaviors toward odors (Mechaber et al., 2002), a persistent effect of odor learning onto olfactory network activity (Daly et al., 2004), and adult volume increases were at least found in antennal lobe glomeruli (Huetteroth and Schachtner, 2005).

With this study we provide a standard female and male brain of freshly eclosed $M$. sexta. These standard brains will serve as a useful tool to study metamorphic brain development adult brain plasticity.

\section{ACKNOWLEDGMENTS}

We thank Dr. E. Buchner (Würzburg, Germany) for supplying us with anti-Synapsin antibody, and Drs. U. Homberg and T. Rohlfing for many fruitful discussions.

\section{LITERATURE CITED}

Alten H. von 1910. Zur Phylogenie des Hymenopterengehirns. Z Naturwiss 46:511-590.

Anton S, Homberg U. 1999. Antennal lobe structure. In: Hansson BS, editor. Insect olfaction. Berlin: Springer. p 97-124.

Arnold G, Masson C, Budharugsa S. 1984. Demonstration of a sexual dimorphism in the olfactory pathways of the drones of Apis-Mellifica L. (Hymenoptera, Apidae). Experientia 40:723-725.

Barth M, Heisenberg M. 1997. Vision affects mushroom bodies and central complex in Drosophila melanogaster. Learn Mem 4:219-229.

Barth M, Hirsch HV, Meinertzhagen IA, Heisenberg M. 1997. Experiencedependent developmental plasticity in the optic lobe of Drosophila melanogaster. J Neurosci 17:1493-1504.

Barton RA, Purvis A, Harvey PH. 1995. Evolutionary radiation of visual and 
olfactory brain systems in primates, bats and insectivores. Philos Trans R Soc London B Biol Sci 348:381-392.

Bell RA, Joachim FA. 1978. Techniques for rearing laboratory colonies of the tobacco hornworm, Manduca sexta and pink ballworms. Ann Entomol Soc Am 69:365-373.

Berg BG, Galizia CG, Brandt R, Mustaparta H. 2002. Digital atlases of the antennal lobe in two species of tobacco budworm moths, the Oriental Helicoverpa assulta (male) and the American Heliothis virescens (male and female). J Comp Neurol 446:123-134.

Boeckh J, Ernst KD, Selsam P. 1987. Neurophysiology and Neuroanatomy of the Olfactory Pathway in the Cockroach. Ann N Y Acad Sci 510:3943.

Brandt R, Rohlfing T, Rybak J, Krofczik S, Maye A, Westerhoff M, Hege HC, Menzel R. 2005. Three-dimensional average-shape atlas of the honeybee brain and its applications. J Comp Neurol 492:1-19.

Brockmann A, Brückner D. 2001. Structural differences in the drone olfactory system of two phylogenetically distant Apis species, $A$. florea and $A$. mellifera. Naturwissenschaften 88:78-81.

Bucher D, Scholz M, Stetter M, Obermayer K, Pflüger HJ. 2000. Correction methods for three-dimensional reconstructions from confocal images: I. Tissue shrinking and axial scaling. J Neurosci Methods 100:135-143.

Camazine SM, Hildebrand JG. 1979. Central projections of antennal sensory neurons in mature and developing Manduca sexta. Soc Neurosci Abstr 5:155.

Christensen TA, Hildebrand JG. 1987. Male-specific, sex pheromoneselective projection neurons in the antennal lobes of the moth Manduca sexta. J Comp Physiol A 160:553-569.

Daly KC, Smith BH. 2000. Associative olfactory learning in the moth Manduca sexta. J Exp Biol 203:2025-2038.

Daly KC, Durtschi ML, Smith BH. 2001. Olfactory-based discrimination learning in the moth, Manduca sexta. J Insect Physiol 47:375-384.

Daly KC, Christensen TA, Lei H, Smith BH, Hildebrand JG. 2004. Learning modulates the ensemble representations for odors in primary olfactory networks. Proc Natl Acad Sci U S A 101:10476-10481.

Dufour MC, Gadenne C. 2006. Adult neurogenesis in a moth brain. J Comp Neurol 495:635-643.

Fukushima R, Kanzaki R. 2009. Modular subdivision of mushroom bodies by kenyon cells in the silkmoth. J Comp Neurol 513:315-330.

Galizia CG, Sachse S, Rappert A, Menzel R. 1999. The glomerular code for odor representation is species specific in the honeybee Apis mellifera. Nat Neurosci 2:473-478.

Garofalo CA. 1978. Bionomics of Bombus (Fervidobombus) morio: 2. Body size and length of life of workers. J Apic Res 17:130-136.

Gould SJ. 1966. Allometry and size in ontogeny and phylogeny. Biol Rev 41:587-638.

Gould SJ. 1975. Allometry in primates, with emphasis on scaling and the evolution of the brain. Contrib Primatol 5:244-292.

Goyret J, Pfaff M, Raguso RA, Kelber A. 2008. Why do Manduca sexta feed from white flowers? Innate and learnt colour preferences in a hawkmoth. Naturwissenschaften 95:569-576.

Groh C, Tautz J, Rössler W. 2004. Synaptic organization in the adult honey bee brain is influenced by brood-temperature control during pupal development. Proc Natl Acad Sci U S A 101:4268-4273.

Groh C, Ahrens D, Rössler W. 2006. Environment- and age-dependent plasticity of synaptic complexes in the mushroom bodies of honeybee queens. Brain Behav Evol 68:1-14.

Gronenberg W, Hölldobler B. 1999. Morphologic representation of visua and antennal information in the ant brain. J Comp Neurol 412:229-240.

Guerenstein PG, Hildebrand JG. 2008. Roles and effects of environmental carbon dioxide in insect life. Annu Rev Entomol 53:161-178.

Guerenstein PG, Christensen TA, Hildebrand JG. 2004. Sensory processing of ambient $\mathrm{CO} 2$ information in the brain of the moth Manduca sexta. J Comp Physiol A 190:707-725.

Guimond A, Meunier J, Thirion JP. 2000. Average brain models: a convergence study. Comput Vis Image Und 77:192-210.

Hansson BS, Anton S. 2000. Function and morphology of the antennal lobe: new developments. Annu Rev Entomol 45:203-231.

Hansson BS, Christensen TA. 1999. Functional characteristics of the antennal lobe. In: Hansson BS, editor. Insect olfaction. Berlin: Springer. p $126-162$.

Hansson BS, Christensen TA, Hildebrand JG. 1991. Functionally distinct subdivisions of the macroglomerular complex in the antennal lobe of the male sphinx moth Manduca sexta. J Comp Neurol 312:264-278.

Hansson BS, Carlsson A, Kalinova B. 2003. Olfactory activation patterns in the antennal lobe of the sphinx moth, Manduca sexta. J Comp Physio A 189:301-308.

Hanström B. 1928. Vergleichende Anatomie des Nervensystems der Wirbellosen Tiere unter Berücksichtigung seiner Funktion. Berlin Springer.

Harvey PH. 1988. Allometric analysis and brain size. In: Jerison HJ, Jerison $\mathrm{I}$, editors. Intelligence and evolutionary biology. Berlin: Springer. p $199-210$.

Heinbockel T, Kloppenburg P, Hildebrand JG. 1998. Pheromone-evoked potentials and oscillations in the antennal lobes of the sphinx moth Manduca sexta. J Comp Physiol A 182:703-714.

Heisenberg M. 2003. Mushroom body memoir: from maps to models. Nat Rev Neurosci 4:266-275.

Heisenberg M, Heusipp M, Wanke C. 1995. Structural plasticity in the Drosophila brain. J Neurosci 15:1951-1960.

Hildebrand JG, Shepherd GM. 1997. Mechanisms of olfactory discrimination: convergent evidence for common principles across phyla. Annu Rev Neurosci 20:595-611.

Hölldobler B, Wilson EO. 1990. The ants. Cambridge MA: Belknap Press. Hölldobler B, Wilson EO. 2008. The superorganism: the beauty, elegance, and strangeness of insect societies. New York: Norton.

Homberg U. 2008. Evolution of the central complex in the arthropod brain with respect to the visual system. Arthropod Struct Dev 37:347-362.

Homberg U, Montague RA, Hildebrand JG. 1988. Anatomy of antennocerebral pathways in the brain of the sphinx moth Manduca sexta. Cell Tissue Res 254:255-281.

Huetteroth W, Schachtner J. 2005. Standard three-dimensional glomeruli of the Manduca sexta antennal lobe: a tool to study both developmental and adult neuronal plasticity. Cell Tissue Res 319:513-524.

Jawlowski H. 1948. Studies on the insect brain. Ann UMCS C Lublin 3:1-30.

Jefferis GSXE, Hummel T. 2006. Wiring specificity in the olfactory system. Semin Cell Dev Biol 17:50-65.

Jefferis GS, Potter CJ, Chan AM, Marin EC, Rohlfing T, Maurer CR Jr, Luo L. 2007. Comprehensive maps of Drosophila higher olfactory centers: spatially segregated fruit and pheromone representation. Cell 128: 1187-1203.

Jenett A, Schindelin JE, Heisenberg M. 2006. The virtual insect brain protocol: creating and comparing standardized neuroanatomy. BMC Bioinformatics 7:544.

Julian GE, Gronenberg W. 2002. Reduction of brain volume correlates with behavioral changes in queen ants. Brain Behav Evol 60:152-164.

Kanzaki R, Soo K, Seki Y, Wada S. 2003. Projections to higher olfactory centers from subdivisions of the antennal lobe macroglomerular complex of the male silkmoth. Chem Senses 28:113-130.

Kazawa T, Namiki S, Fukushima R, Terada M, Soo K, Kanzaki R. 2009. Constancy and variability of glomerular organization in the antennal lobe of the silkmoth. Cell Tissue Res [Epub ahead of print, DOI 10.1007/s00441-009-0756-3].

Kent KS, Harrow ID, Quartararo P, Hildebrand JG. 1986. An accessory olfactory pathway in Lepidoptera: the labial pit organ and its central projections in Manduca sexta and certain other sphinx moths and silk moths. Cell Tissue Res 245:237-245.

Kimura K, Ote M, Tazawa T, Yamamoto D. 2005. Fruitless specifies sexually dimorphic neural circuitry in the Drosophila brain. Nature 438: 229-233.

King JR, Christensen TA, and Hildebrand JG. 2000. Response characteristics of an identified, sexually dimorphic olfactory glomerulus. J Neurosci 20:2391-2399.

Klagges BR, Heimbeck G, Godenschwege TA, Hofbauer A, Pflugfelder GO, Reifegerste R, Reisch D, Schaupp M, Buchner S, Buchner E. 1996. Invertebrate synapsins: a single gene codes for several isoforms in Drosophila. J Neurosci 16:3154-3165.

Kleineidam CJ, Obermayer M, Halbich W, Rössler W. 2005. A macroglomerulus in the antennal lobe of leaf-cutting ant workers and its possible functional significance. Chem Senses 30:383-392.

Kondoh Y, Kaneshiro KY, Kimura K, Yamamoto D. 2003. Evolution of sexual dimorphism in the olfactory brain of Hawaiian Drosophila. Proc Biol Sci 270:1005-1013.

Korsching S. 2002. Olfactory maps and odor images. Curr Opin Neurobiol 12:387-392.

Kurylas AE, Rohlfing T, Krofczik S, Jenett A, Homberg U. 2008. Standardized atlas of the brain of the desert locust, Schistocerca gregaria. Cell Tissue Res 333:125-145. 
Ku $\beta$ A, Hege HC, Krofczik S, Borner J. 2007. Pipeline for the creation of surface-based averaged brain atlases. Proc WSCG 1:17-24.

Lee JK, Strausfeld NJ. 1990. Structure, distribution and number of surface sensilla and their receptor cells on the olfactory appendage of the male moth Manduca sexta. J Neurocytol 19:519-538.

Leon M, Johnson BA. 2003. Olfactory coding in the mammalian olfactory bulb. Brain Res Rev 42:23-32.

Lipscomb BW, Tolbert LP. 2006. Temporally staggered glomerulus development in the moth Manduca sexta. Chem Senses 31:237-247.

Mares S, Ash L, Gronenberg W. 2005. Brain allometry in bumblebee and honey bee workers. Brain Behav Evol 66:50-61.

Masante-Roca I, Gadenne C, Anton S. 2002. Plant odour processing in the antennal lobe of male and female grapevine moths, Lobesia botrana (Lepidoptera: Tortricidae). J Insect Physiol 48:1111-1121.

Matsumoto SG, Hildebrand JG. 1981. Olfactory mechanisms in the moth Manduca sexta: response characteristics and morphology of central neurons in the antennal lobes. Proc R Soc Lond B 213:249-277.

Mechaber WL, Capaldo CT, Hildebrand JG. 2002. Behavioral responses of adult female tobacco hornworms, Manduca sexta, to hostplant volatiles change with age and mating status. J Insect Sci 2:5.

Menzel R. 2001. Searching for the memory trace in a mini-brain, the honeybee. Learn Mem 8:53-62.

Milde JJ. 1993. Tangential medulla neurons in the moth Manduca sexta. Structure and responses to optomotor stimuli. J Comp Physiol A 173:783-799.

Molina Y, O'Donnell S. 2008. Age, sex, and dominance-related mushroom body plasticity in the paperwasp Mischocyttarus mastigophorus. Dev Neurobiol 68:950-959.

Mombaerts P. 2006. Axonal wiring in the mouse olfactory system. Annu Rev Cell Dev Biol 22:713-37.

Namiki S, Kanzaki R. 2008. Reconstructing the population activity of olfactory output neurons that innervate identifiable processing units. Front Neural Circuits 2:1.

Neder R. 1959. Allometrisches Wachstum von Hirnteilen bei drei verschieden großen Schabenarten. Zool Jb Abt Zool Physiol 77:411-467.

Nishikawa M, Nishino H, Misaka Y, Kubota M, Tsuji E, Satoji Y, Ozaki M, Yokohari F. 2008. Sexual dimorphism in the antennal lobe of the ant Camponotus japonicus. Zool Sci 25:195-204.

Nordström K, Barnett PD, Moyer dM, I, Brinkworth RS, O'Carroll DC. 2008 Sexual dimorphism in the hoverfly motion vision pathway. Curr Biol 18:661-667.

Ott SR. 2008. Confocal microscopy in large insect brains: zincformaldehyde fixation improves synapsin immunostaining and preservation of morphology in whole-mounts. J Neurosci Methods 172:220230.

Pearson L. 1971. The corpora pedunculata of Sphinx ligustri L. and other Lepidoptera: an anatomical study. Proc R Soc Lond B 259:477-516.

Rein K, Zöckler M, Mader MT, Grübel C, Heisenberg M. 2002. The Drosophila standard brain. Curr Biol 12:227-231.

Reisenman CE, Christensen TA, Francke W, Hildebrand JG. 2004. Enantioselectivity of projection neurons innervating identified olfactory glomeruli. J Neurosci 24:2602-2611.

Reppert SM. 2006. A colorful model of the circadian clock. Cell 124:233236.

Riffell JA, Alarcon R, Abrell L, Davidowitz G, Bronstein JL, Hildebrand JG. 2008. Behavioral consequences of innate preferences and olfactory learning in hawkmoth-flower interactions. Proc Natl Acad Sci U S A 105:3404-3409.

Rø H, Müller D, Mustaparta H. 2007. Anatomical organization of antennal lobe projection neurons in the moth Heliothis virescens. J Comp Neurol 500:658-675.

Rohlfing T, Brandt R, Maurer CR Jr, Menzel R. 2001. Bee brains, B-splines and computational democracy: generating an average shape atlas. Proc IEEE Workshop on Mathematical Methods in Biomedical Image Analysis, MMBIA, Kauai, Hawaii, December, 2001. p 187-194.

Rohlfing T, Brandt R, Menzel R, Maurer CR Jr. 2004. Evaluation of atlas selection strategies for atlas-based image segmentation with application to confocal microscopy images of bee brains. Neuroimage 21: $1428-1442$.
Rospars JP, Hildebrand JG. 2000. Sexually dimorphic and isomorphic glomeruli in the antennal lobes of the sphinx moth Manduca sexta. Chem Senses 25:119-129.

Schachtner J, Schmidt M, Homberg U. 2005. Organization and evolutionary trends of primary olfactory brain centers in Tetraconata (Crustacea + Hexapoda). Arthropod Struct Dev 34:257-299.

Schneiderman AM, Matsumoto SG, Hildebrand JG. 1982. Trans-sexually grafted antennae influence development of sexually dimorphic neurones in moth brain. Nature 298:844-846.

Schoenemann PT. 2006. Evolution of the size and functional areas of the human brain. Annu Rev Anthropol 35:379-406.

Sigg D, Thompson CM, Mercer AR. 1997. Activity-dependent changes to the brain and behavior of the honey bee, Apis mellifera (L.). J Neurosci 17:7148-7156.

Sivinski J. 1989. Mushroom body development in nymphalid butterflies: a correlate of learning? J Insect Behav 2:277-283.

Sjöholm M, Sinakevitch I, Ignell R, Strausfeld NJ, Hansson BS. 2005. Organization of Kenyon cells in subdivisions of the mushroom bodies of a lepidopteran insect. J Comp Neurol 491:290-304.

Staudacher EM, Huetteroth W, Schachtner J, Daly KC. 2009. A 4D representation of antennal lobe output based on an ensemble of characterized projection neurons. J Neurosci Methods 180:208-223.

Strausfeld NJ. 1991. Structural organization of male-specific visual neurons in calliphorid optic lobes. J Comp Physiol A 169:379-393.

Strausfeld NJ. 2005. The evolution of crustacean and insect optic lobes and the origins of chiasmata. Arthropod Struct Dev 34:235-256.

Strausfeld NJ, Hansen L, Li Y, Gomez RS, Ito K. 1998. Evolution, discovery, and interpretations of arthropod mushroom bodies. Learn Mem 5:11-37.

Strauss R. 2002. The central complex and the genetic dissection of locomotor behaviour. Curr Opin Neurobiol 12:633-638.

Technau GM. 2007. Fiber number in the mushroom bodies of adult Drosophila melanogaster depends on age, sex and experience. J Neurogenet 21:183-196.

Terada M, Kazawa T, Seki Y, Kanzaki R. 2003. Three-dimensional reconstruction and identification of the antennal lobe glomerular structures in Bombyx mori. Zool Sci 20:1580.

Tolbert LP, Oland LA, Tucker ES, Gibson NJ, Higgins MR, Lipscomb BW. 2004. Bidirectional influences between neurons and glial cells in the developing olfactory system. Prog Neurobiol 73:73-105.

Utz S, Huetteroth W, Vömel M, Schachtner J. 2008. Mas-allatotropin in the developing antennal lobe of the sphinx moth Manduca sexta: distribution, time course, developmental regulation, and colocalization with other neuropeptides. Dev Neurobiol 68:123-142.

Vosshall LB. 2000. Olfaction in Drosophila. Curr Opin Neurobiol 10:498503.

Vosshall LB, Stocker RF. 2007. Molecular architecture of smell and taste in Drosophila. Annu Rev Neurosci. 30:505-533.

Wang JW, Wong AM, Flores J, Vosshall LB, Axel R. 2003.Two-photon calcium imaging reveals an odor-evoked map of activity in the fly brain. Cell 112:271-282.

Weevers RD. 1966. A lepidopteran saline: effects of inorganic cation concentrations on sensory, reflex and motor responses in a herbivorous insect. J Exp Biol 44:163-175.

Wehner R. 1981. Spatial vision in arthropods. In: Autrum H, editor. Handbook of sensory physiology. Berlin: Springer. p 471-592.

Wehner R, Fukushi T, Isler K. 2007. On being small: brain allometry in ants. Brain Behav Evol 69:220-228.

Wessnitzer J, Webb B. 2006. Multimodal sensory integration in insects towards insect brain control architectures. Bioinspir Biomim 1:63-75.

Wicklein M, Strausfeld NJ. 2000. Organization and significance of neurons that detect change of visual depth in the hawk moth Manduca sexta. J Comp Neurol 424:356-376.

Wilson EO. 1971. The insect societies. Cambridge MA: Harvard University Press.

Winston ML. 1987. The biology of the honey bee. Cambridge MA: Harvard University Press.

Zeil J. 1983. Sexual dimorphism in the visual system of flies: the divided brain of male Bibionidae (Diptera). Cell Tissue Res 229:591-610. 